\title{
Multifunctional nanostructured PLA materials for packaging and tissue engineering
}

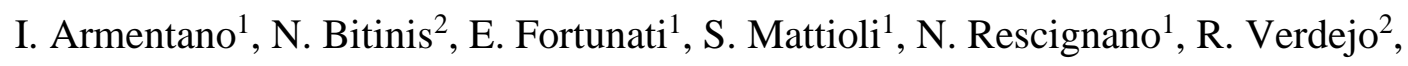 \\ M.A. Lopez-Manchado ${ }^{2 *}$ J.M. Kenny ${ }^{1,2}$ \\ ${ }^{1}$ Materials Engineering Center, UdR INSTM, University of Perugia, 05100 Terni, Italy \\ ${ }^{2}$ Instituto de Ciencia y Tecnología de Polímeros, ICTP-CSIC, Juan de la Cierva, 3 \\ 28006 Madrid, Spain
}

\begin{abstract}
This review reports the promising prospects of poly(lactic acid) (PLA) based nanostructured materials considering two of their main potential uses, packaging and tissue engineering. The review initially discusses the significant progresses in the development of PLA bionanocomposites for packaging applications. The review then continues with a comprehensive analysis of the recent advances in tissue engineering applications focusing in the synthesis of PLA nanoparticles, the processing of PLA based multifunctional nanocomposites and PLA surface modification techniques. In summary, the review presents the current state of nanostructured PLA materials and establishes the exciting present and future prospects of these materials at the interface of chemistry, biology and material science.
\end{abstract}

Keywords: PLA; packaging; tissue engineering; nanoparticles; bionanocomposites; nanotopography.

*Corresponding author. e-mail: Imanchado@ictp.csic.es 


\section{List of symbols and abbreviations}

ACN

AFM

$\mathrm{Ag}$

C15A

C20A

C25A

C30B

CCVD

$\mathrm{CL}$

CNC

CNFs

CNTs

DMA

ECM

ESCs

FDA

g-HAP

$T_{g}$

GTR

HAP

hBM-MSCs

hMSCs

iPSCS

LA

mBM-MSCs

MFC

MMT

MWCNTs

nHAP

NPs

NR
Acetylated cellulose nanocrystals

Atomic force microscopy

Silver nanoparticles

Cloisite ${ }^{\circledast}$ C15A

Cloisite ${ }^{\oplus}$ C20A

Cloisite ${ }^{\circledast}$ C25A

Cloisite ${ }^{\circledast}$ C30B

Catalytic chemical vapour deposition

Caprolactone

Cellulose nanocrystals

Carbon nanofibres

Carbon nanotubes

Dynamic mechanical analysis

Extra-cellular matrix

Embryonic stem cells

Food and drug administration

Graft-HAP

Glass transition temperature

Guided tissue regeneration

Hydroxyapatite

Human mesenchymal stem cells Isolated from bone marrow

Human mesenchymal stem cells

Induced pluripotent stem cells

Lactic acid

Murine bone marrow mesenchymal stem cells

Microfibrillated cellulose

Montmorillonite

Multiwall carbon nanotubes

Nano-sized hydroxyapatite

Nanoparticles

Natural rubber 


\begin{tabular}{|c|c|}
\hline OCT-1 & Osteoblast-like cells \\
\hline PBS & Poly(butylene succinate) \\
\hline PBSA & Poly(butylene succinate-co-butylene adipate) \\
\hline$p c$ & Percolation threshold \\
\hline PCL & Poly( $\varepsilon$-caprolactone) \\
\hline PDLLA & Poly((D,L)-lactic acid) \\
\hline PEG & Poly(ethylene glycol) \\
\hline PEI & Poly(ethylenimine) \\
\hline PET & Poly(ethylene terephthalate) \\
\hline PGA & Poly(glycolic acid) \\
\hline PLA & Poly(lactic acid) \\
\hline PLDLA & Poly(L,D-lactic acid) \\
\hline PLGA & Poly(Lactic-co-glycolic acid) \\
\hline PLLA & Poly(L-Lactic acid) \\
\hline PLLA/d-HAP & Poly(L-Lactic acid)/Ca-deficient-hydroxyapatite \\
\hline $\operatorname{poly}(C L-c o-D, L-L A)$ & Poly (( $\varepsilon$-caprolactone)-co-D,L-Lactic Acid) \\
\hline $\operatorname{poly}(C L-C o-L-L A)$ & Poly (( $\varepsilon$-caprolactone)-co-L-Lactic acid) \\
\hline $\mathrm{PO}_{2}$ & Gas permeability coefficient of $\mathrm{O}_{2}$ \\
\hline PS & Poly(styrene) \\
\hline$\rho$ & Electrical resistivity \\
\hline ROP & Ring opening polymerisation \\
\hline ROMP & Ring-opening metathesis polymerisation \\
\hline$\sigma$ & Electrical conductivity \\
\hline SAXS & Small angle $X$-ray scattering \\
\hline SBF & Simulated body fluid \\
\hline SDS & Sodium dodecylsulfate \\
\hline SWCNTS & Single wall carbon nanotubes \\
\hline SWCNTS-COOH & Carboxilyc acid functionalised single wall carbon nanotubes \\
\hline TCP & Tricalcium phosphate \\
\hline TEMPO & 2,2,6,6-tetramethyl piperidine-1-oxyl \\
\hline TFC & Twice functionalised organoclay \\
\hline
\end{tabular}


TGA

TIPS

TPS

WAXS
Thermogravimetric analysis

Thermally induced phase separation

Thermoplastic starch

Wide angle $\mathrm{X}$-ray scattering 


\section{Table of contents}

1. Introduction 1

2. PLA bionanocomposites for packaging applications 2

2.1. PLA merits 2

2.2. PLA bionanocomposites properties 5

2.2.1. Mechanical properties 5

2.2.2. Gas barrier properties 6

2.2.3. Crystallisation behaviour 9

2.2.4. Acceleration of PLA biodegradation process 11

2.2.5. Thermal stability 13

2.2.6. Transparency 14

2.2.7. Synergetic improvement of PLA properties 14

3. PLA in tissue engineering: Nanoparticle, nanocomposites and $\begin{array}{ll}\text { nanotopography } & 20\end{array}$

3.1. Nanoparticles 22

3.1.1. Preparation of nanoparticles 23

3.1.2. Nanoparticle properties 24

3.1.3. Drug loading and drug release mechanisms 25

3.1.4. Nanoparticles and cell interaction 26

3.2. Nanocomposite concepts in the biomedical field 27

3.2.1. Processing strategies for nanocomposite scaffolds 30

3.2.2. Mechanical properties of PLA nanocomposite scaffolds 33

3.2.3. Electrical properties of PLA nanocomposite scaffolds 35

3.3. PLA nanotopography and cellular response 37

3.3.1. Nanofabrication and surface modification methods 38

3.3.2. Cell response to PLA nanotopography 39

4. Conclusions 42 


\section{Introduction}

The term "biopolymers" is generally understood as biodegradable polymers, i.e. polymers capable of breaking down cleanly into simple molecules found in the environment, such as carbon dioxide, water or methane, under the enzymatic action of microorganisms, in a defined period of time (European standard EN 13432). However, polymers derived from natural resources, or "biosourced" polymers, are also considered as biopolymers. Being biosourced does not systematically imply to be biodegradable and vice-versa. Therefore, a clear classification of the different biopolymers is necessary to clarify these different concepts. Bordes et al. [1] suggested a classification of biopolymers solely based on biodegradable polymers. However, a broader definition should also consider the biosourced polymers. So, a classification of the different types of biopolymers is shown in Figure 1:

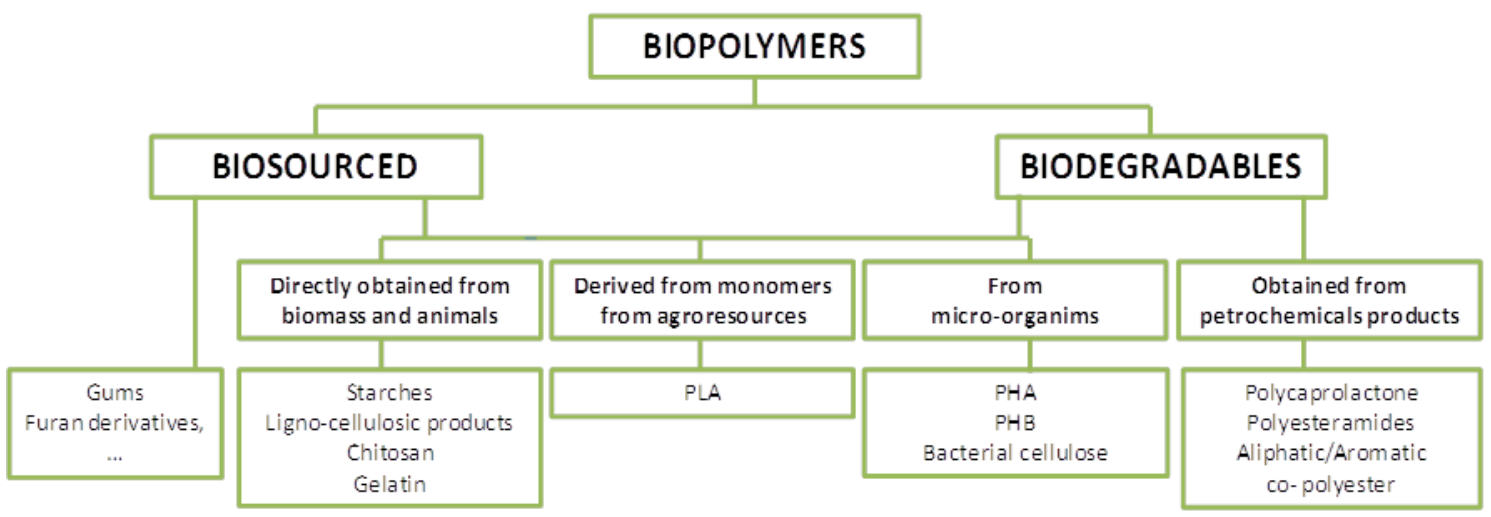

Figure 1. Classification of the different types of biopolymers (adapted Bordes et al. [1])

One of the most promising biopolymers able to replace the petroleum-derived polymers for industrial applications is poly(lactic acid) (PLA). PLA is a linear aliphatic thermoplastic polyester derived from $100 \%$ renewable resources such as sugar, corn, potatoes, cane, beet, etc. The most common route for industrial production of high molecular weight PLA is the ring opening polymerisation (ROP) of lactide momoner formed from lactic acid, which is produced by fermentation of renewable agricultural resources [2]. Industrial PLA is mostly composed of poly(L-lactic acid) (PLLA) and poly(L,D-lactic acid) (PLDLA), being the Lisomer the main fraction. PLA possesses interesting physical properties together with biocompatibility and biodegradability properties, which are all strongly influenced by its stereochemistry and molecular weight. In addition, it is easily processed into a desired configuration on standard plastics equipment to yield moulded parts, films or fibres [3]. Owing to these properties, PLA has a wide range of potential industrial applications. Due to 
its initial production costs, the starting applications of PLA have been focused on high value products, particularly medical devices [4]. However, its price has been falling as production increases and new methodologies for high molecular weight PLA are developed [5]. PLA's potential for consumer products such as packaging is remarkable due to its transparency, low toxicity and environmentally benign characteristics [6]. Nevertheless, there are some drawbacks, such as its high brittleness, poor crystallisation behaviour and low gas barrier properties that limit its current use [7].

Hence, this review describes recent strategies for the development of improved poly(lactic acid) based bionanocomposites materials focusing on two of its main potential applications: packaging and tissue engineering. First, the review discusses the most significant advances in the development of PLA nanocomposites for packaging applications. The second part of the review then focuses on the synthesis and biomedical application of nanostructured PLA based biomaterials: nanoparticles, nanocomposites and nanotopography in tissue engineering applications, with particular attention to the current research activities on the cell interaction of PLA nanostructured systems.

\section{PLA bionanocomposites for packaging applications}

\subsection{PLA merits}

Packaging materials must extend shelf-life of the product preventing its deterioration due to physicochemical or biological factors, and preserve or increase the overall quality and safety during storage and handling. In addition, after their useful life, it is desirable that the materials biodegrade in a reasonable time period to avoid environmental waste disposal problems. Therefore, there is an increasing demand for the use of biodegradable polymers originated from renewable sources as alternative to petroleum-based polymers for packaging materials since they can minimize environmental pollution. Among them, poly(lactic acid) (PLA) is the biopolymer most widely used at industrial level $[8,9]$.

PLA exhibits several advantages in relation to the petroleum-based polymers usually used for packaging:

i) Good transparency, usually defined as the transmission of visible light in the range of 540-560 nm, slightly higher than that of poly(ethylene terephthalate) (PET) and poly(styrene) (PS). 
ii) Degradation in biological environment such as soil or compost [10]. The degradation of PLA takes place in two main stages, which are the hydrolytic and enzymatic degradation. The hydrolysis starts with the diffusion of water into the polymer and leads to random nonenzymatic chain scissions of the ester group (Figure 2). The cleavage of ester linkages results in the reduction of the molecular weight and in the formation of oligomers and lactic acid that can be assimilated by microorganisms such as fungi and bacteria [11]. A molecular weight of about 10000-20000 $\mathrm{g} \cdot \mathrm{mol}^{-1}$ appears to be the critical upper limit that microbes can metabolize and then convert to carbon dioxide, water and humus. While the first hydrolytic step can occur in the bulk polymer through the diffusion of water into the polymer, the second step caused by microbes only occurs at the surface $[12,13]$.

a.
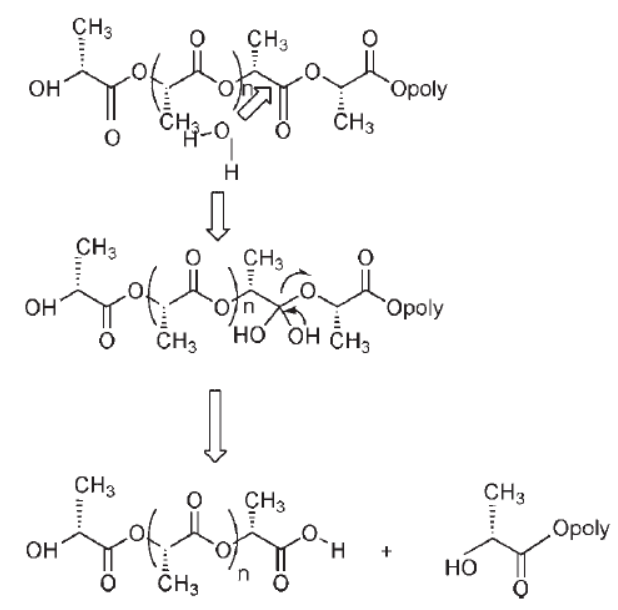

b.

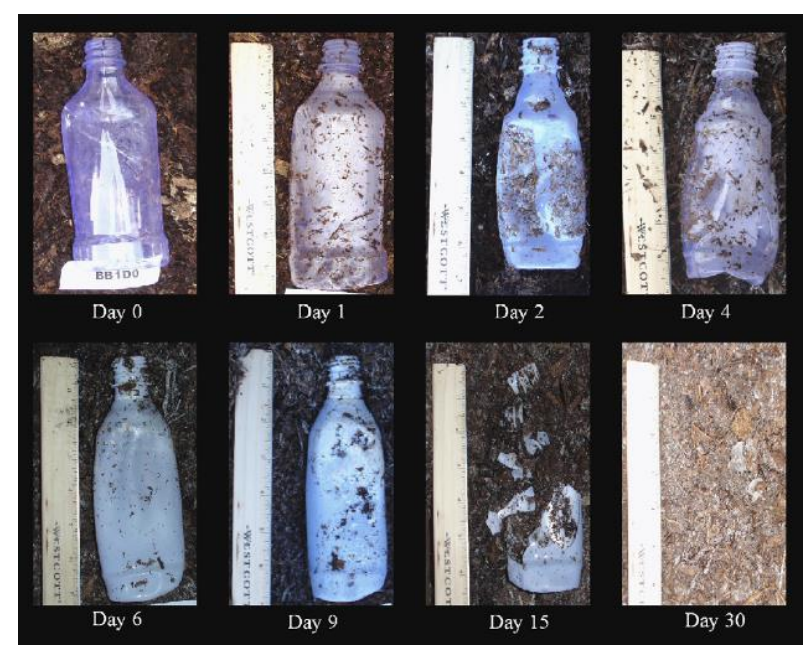

Figure 2. (a) PLA hydrolysis and molecular weight loss [2] and (b) biodegradation of a PLA bottle in real composting condition [12]. Reprinted with permission from Refs. [2] and [12].

iii) Biocompatibility. PLA has been demonstrated to be biocompatible and to degrade into non-toxic components and it has been approved by the Food and Drug Administration (FDA) for implantation in the human body. Since PLA could undergo scission in the body to monomeric units of lactic acid as a natural intermediate in carbohydrate metabolism, it has been incorporated in some established applications such as medical implants and drugdelivery systems [14-22]. The PLA hydrolysis occurs in-vivo and it does not require the presence of enzymes to catalyse it. The rate of degradation is dependent on the size and shape of the polymer, the isomer ratio, the temperature of hydrolysis [23, 24], the presence of lowmolecular weight impurities and the catalyst concentration [25]. Based on available data to 
date, the duration of degradation can last from 1 to 2 years [9]. The degradation of PLA produces lactic acid, which naturally occurs in the metabolism [24, 26-28].

iv) Processability. The main conversion approaches of PLA are based on melt processing. Commercial grades of PLA can typically be processed using a conventional twin-screw extruder and melt viscosities of high molecular weight PLA are in the order of 500 to 1000 $\mathrm{Pa} \cdot \mathrm{s}$ at shear rates of $10-50 \mathrm{~s}^{-1}$. In fact, NatureWorks provides various grades of PLA specifically tailored to each processing and application, such as extrusion, thermoforming, injection stretch blow moulding or film, fibre and foam production [2]. However, its thermal degradation is the main drawback for processing in molten state. PLA thermal degradation can be attributed to hydrolysis, depolymerisation, oxidative random-chain scission, inter- and intramolecular transesterification, resulting in the formation of lactide monomer and oligomers [29]. Residual monomer and traces of water strongly influence the early molecular weight reduction. Therefore, drying PLA pellets before processing is of major importance.

All these features make PLA a sustainable alternative to petrochemical-derived synthetic polymers to be used as packaging material. However, commercial PLA also presents some drawbacks that restrict its current use in food packaging applications $[30,31]$ such as:

- its high brittleness that limits its use in flexible films, sheets or injected parts with high impact strength and reduces the range of processability (mainly blown-film and thermoforming).

- its poor crystallisation behaviour that limits its thermo-mechanical resistance.

- its high hydrolysis rate and low thermal resistance that make PLA unsuitable for hot filling liquid food packaging.

- its low gas barrier properties to $\mathrm{O}_{2}, \mathrm{CO}_{2}$ or $\mathrm{H}_{2} \mathrm{O}$ which are susceptible to react or damage the food.

Many research efforts have been directed towards overcoming these limitations, such as the addition of natural additives and plasticisers, copolymerisation and blending with polymers $[32,33]$.

Though such efforts indicated a significant improvement in PLA properties, still its physical, thermal, and mechanical properties are unacceptable and hinder its practical exploitation. Over the past years, a new approach is being carried out through the development of biomerbased nanocomposites (bionanocomposites) that combine the excellent properties of synthetic polymer nanocomposites (improved mechanical properties, higher thermal stability, altered 
electrical and optical properties, and improved barrier properties) with the intrinsic characteristics of the biopolymers like biocompatibility and biodegradability [34-36].

Since in this special issue, other authors will conduct a thorough review of the most significant findings undertaken in the bionanocomposites field, we will only refer to the properties which are essential for PLA application in the packaging industry.

\subsection{PLA bionanocomposites properties}

\subsubsection{Mechanical properties}

Due to the high interfacial area of nanoparticles, mechanical enhancement is observed for very low loading fractions (up to $10 \mathrm{wt} .-\%$ ). Moreover, a further increase of the nanofiller content could lead to property deteriorations due to the likely formation of agglomerates. Mechanical properties of PLA nanocomposites are mainly evaluated by tensile properties.

The dispersion of the clays is of major importance regarding the tensile properties. Rhim et al. [37] observed a decrease in the tensile strength and the elongation when adding 5 wt.- $\%$ of unmodified clay and organoclays (C20A and $\mathrm{C} 30 \mathrm{~B})$ to the PLA matrix, attributing this reduction to a poor dispersion of the clays. Overall, an enhancement of the tensile modulus of PLA-organoclay nanocomposites is observed, due to the addition of rigid inorganic fillers with high modulus and to the high surface area of clays exposed to the polymer. The variation of tensile strength depends strongly on polymer-filler compatibility. So, low interactions result in the appearance of cavities between the matrix and nanoparticles while stretching, leading to premature yielding. Likewise, a reduction of elongation at break is usually observed [38].

Nevertheless, some authors reported an interesting toughening effect of layered silicates. Lewitus et al. [39] observed an increase of tensile modulus and elongation at break by $37 \%$ and $48 \%$ respectively with the addition of 5 wt.- $\%$ of organoclay using a masterbatch processing method. However, no changes were observed for tensile strength compared to neat PLA. They concluded that the toughening effect was due to interactions at molecular level and to a high degree of exfoliation. In a similar way, Li et al. [40] observed an increase of the elongation at break of up to $200 \%$ with the addition of 1 wt.- $\%$ of organically modified rectorite to the PLA matrix. Further increase of the clay content led to a decrease of this value, while the modulus gradually increased with clay content and tensile strength decreased. The mechanisms responsible for the toughening effect of the clays were analysed through the 
observation of the samples after tensile tests using scanning electron microscopy. They concluded that debonding of the clay from the PLA matrix facilitated the plastic deformation of PLA.

Tensile properties of PLA/bioparticles nanocomposites present similar characteristics to layered silicate nanocomposites. The improvement of the Young's modulus is attributed to the high modulus of the rigid nanocrystals while tensile strength changes depended on filler surface modifications. Figure 3 reports the results obtained by Lin et al. [41] with the addition of acetylated CNC (noted ACN). All the PLA/ACN nanocomposites exhibited dramatically increased Young's modulus meanwhile the evolution of the elongation at break was just the opposite, due to the presence of rigid nanocrystals. The tensile strength at break reached a maximum for 6 wt.- $\%$ loading. It is believed that when an excess of nanofiller was added, a rigid network formed among the nanocrystals in the composites as well as self-aggregation, resulting in a decrease in the strength and elongation.

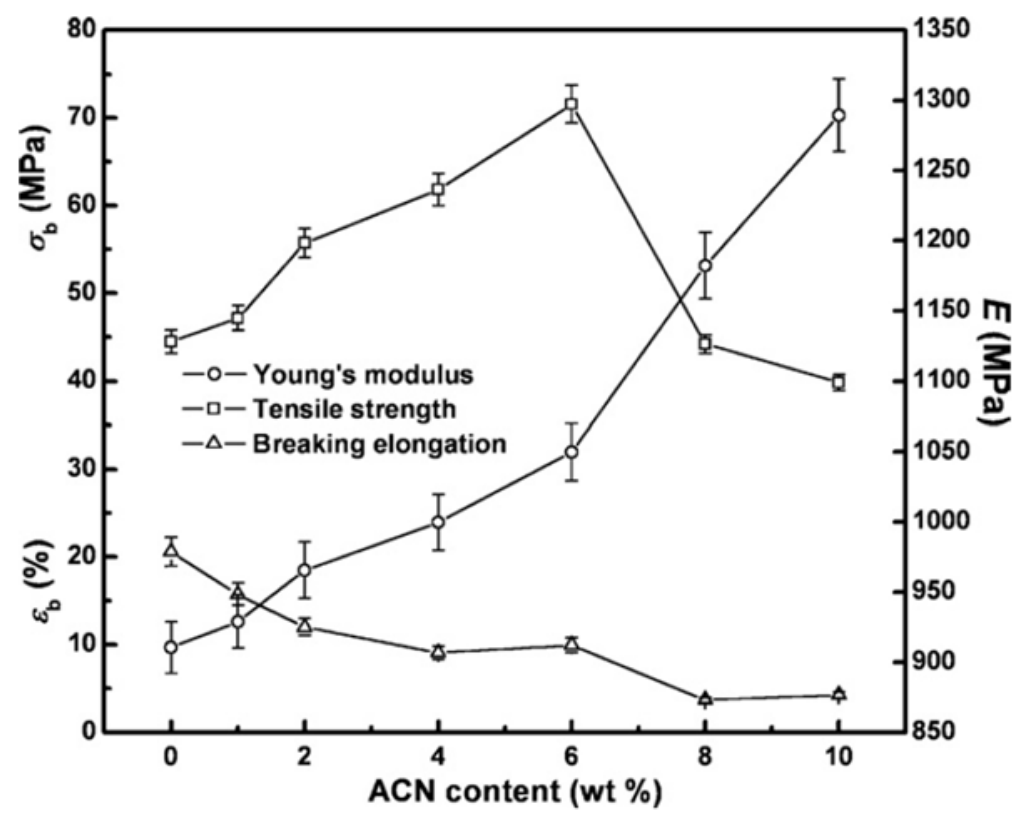

Figure 3. Effect of the acetylated CNC (ACN) content on $\varepsilon_{b}$, $\sigma_{b}$ and E for PLA/ACN nanocomposites (measurement carried out at $10 \mathrm{~mm} \cdot \mathrm{min}^{-1}$ ). Reprinted with permission from Ref. [41]

\subsubsection{Gas barrier properties}

Gas barrier properties are governed by the permeation and diffusion of gas molecules through the polymer membrane. The process is rather complex and involves the free volume holes of the polymer chains resulting from the Brownian motions of the chains or by thermal 
perturbations [42]. Hence, the most frequently used strategy to improve the barrier properties is by inhibit this mass transport through the inclusion of non-permeable barriers that create a tortuous pathway. This tortuous pathway has been pursued by three different approaches: i) increasing the polymer crystallinity, since the crystallites are impermeable to small molecules, ii) adding nanofillers, and iii) forming multilayers.

The relationship between PLA crystallinity degree and gas barrier properties is still a subject of debate. While initial studies [43,44] reported a decrease of the permeability of PLA films with increasing crystallinity; recent studies observed no effect on the oxygen and helium [45] and water [46, 47] permeability. The authors attributed the results to either the crystal polymorphism and PLA stereochemistry $[45,46]$ or the crystalline and amorphous phase organizations [47].

The most followed strategy to create a tortuous pathway in PLA has been the incorporation of nanofillers and, in particular, layered silicates and cellulose nanowhiskers because of their environmental friendliness and natural abundance. Although sheet-like morphology fillers are particularly efficient due to the large length-to-width ratio [48], only few results have been reported on PLA/clay systems [49-52]. Ray et al. [50] compared the effect of four types of organoclays, i.e. montmorillonites, saponite and mica with different interlayer cations. They determined the aspect ratio of the layered silicates in the nanocomposites from TEM images and calculated the theoretical value of the gas barrier relative coefficient $\left(\mathrm{P}_{\text {nanocomposites }} / \mathrm{P}_{\mathrm{PLA}}\right)$ for the $\mathrm{O}_{2}$ permeability from Nielsen model [42]. The experimental values matched quite well the theoretical ones, except for the saponite modified with a hydroxylated cation for which the experimental value was lower than the theoretical one. The difference was attributed to the good interaction of this layered silicate with PLA matrix. Exfoliated nanostructure gave the strongest gas permeability decrease. More recently, Picard et al. [52] analysed the combined effect of organoclays with their crystallisation nucleating effect reporting a permeability decrease for annealed crystalline film containing 4 wt.- $\%$ of montmorillonite with respect to the amorphous reference PLA film. Moreover, it has been reported that orienting and parallel ordering of the layered silicates induced by extrusion blow moulding can further decrease the $\mathrm{O}_{2}$ transmission [53]. In general, PLA/organoclay nanocomposites prepared by traditional methods showed a maximum of $60 \%$ reduction of the oxygen permeability coefficient for a clay content of about 5-10 wt.-\%. Higher contents led to the formation of aggregates that hindered further improvements. Another strategy to tune the permeability of a ductile PLA nanocomposite blend is by considering the nanofiller nature and by changing the mixing 
procedure and, hence, obtaining a specific location of the clays (Figure 4) [54]. The authors studied the permeability of $\mathrm{O}_{2}$ and $\mathrm{CO}_{2}$ in a PLA/NR blend with a fixed concentration of $\mathrm{C} 15 \mathrm{~A}$ and $\mathrm{C} 30 \mathrm{~B}$. They observed a marked reduction of gas flux, from $\mathrm{P}_{2}=1.01$ Barrers for PLA/NR to $\mathrm{P} \mathrm{O}_{2}=0.86$ for PLA/NR/C30B 3 wt. $-\%$, when the C30B organoclay was added to the blend due to its better compatibility with PLA. While, a similar or increased permeability values compared to the unfilled sample were obtained with the addition of $\mathrm{C} 15 \mathrm{~A}$ due to its affinity with the dispersed NR phase. A further decrease of the permeability, to $\mathrm{P}_{2}=0.68$ Barrers, was obtained when the organoclay C30B was pre-blended with PLA for $10 \mathrm{~min}$ before adding the NR.
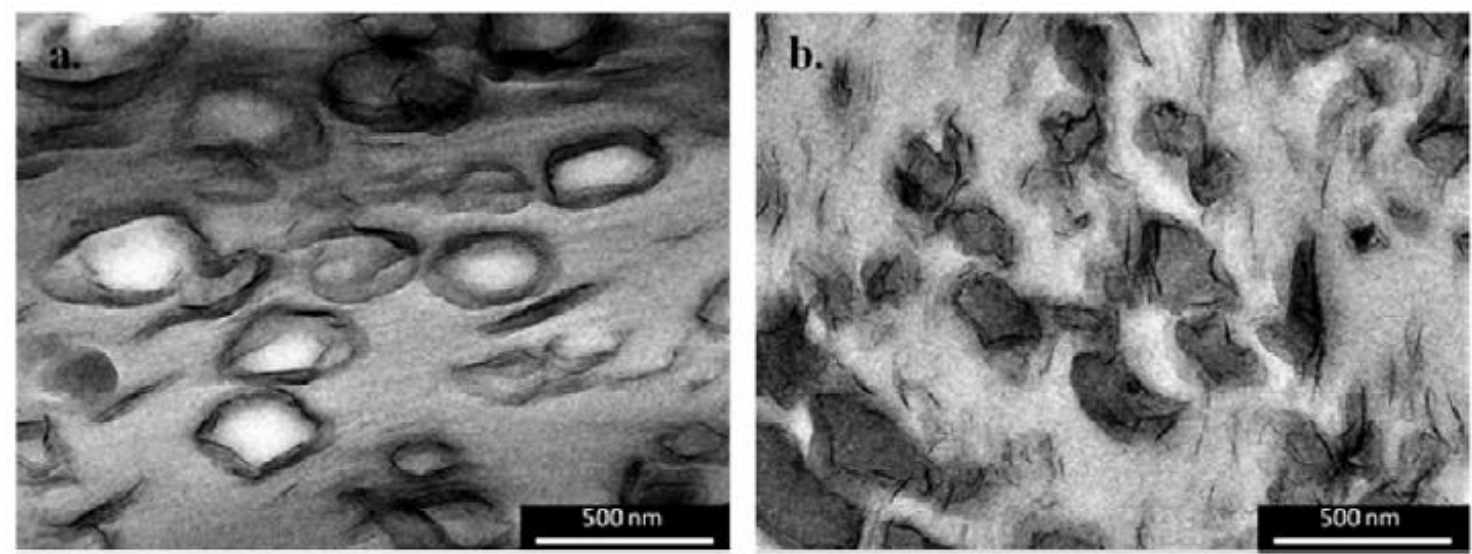

Figure 4. TEM images of the nanocomposites: (a) PLA/NR/C3OB and (b) pre-blending (PLA/C30B) followed by NR blend. Reprinted with permission from Ref. [54].

Gas barrier properties of PLA/cellulose nanoparticles have also been described in the literature, especially by Sanchez-Garcia et al. [55, 56]. Interestingly, they compared the effect of the same content of cellulose microfibres and cellulose nanocrystals. The addition of 5 wt.$\%$ of MFC had no effect over gas barrier properties while 5 wt.-\% of CNC led to a decrease of $90 \%$ in oxygen permeability.

The multilayer approach has only received minor attention. Most authors have focused on possibility to make an entire biobased multilayer system. A bi-layer sample composed of filtered 2,2,6,6-tetramethylpiperidine-1-oxyl (TEMPO)-radical oxidised cellulose nanofibres and PLA was reported by Fukuzumi et al. [57] The oxygen permeability of PLA film drastically decreased, from $746 \mathrm{~mL} \mathrm{~m}^{-2}$ day $^{-1} \mathrm{~Pa}^{-1}$ to $1 \mathrm{~mL} \mathrm{~m}^{-2}$ day ${ }^{-1} \mathrm{~Pa}^{-1}$ due to the thin layer of oxidised cellulose nanofibres. Tri-layer systems have been proposed by Martucci and Ruseckaite [58] with glycerol-plasticised gelatine as the inner layer. They observed a decrease of the oxygen permeability $\left(17.1 \pm 2.3 \mathrm{~cm}^{3}\left(\mathrm{O}_{2}\right) \cdot \mathrm{mm} \cdot \mathrm{m}^{-2} \cdot \mathrm{day}^{-1}\right)$ was reduced compared to that 
of neat PLA. The latest combination of the nanocomposite and multilayer approaches was reported using the layer-by-layer methodology and provided the best results so far [59]. Very thin laminar multilayer structures of chitosan and MMT were assembled as a result of the electrostatic forces on the PLA film. When the PLA films were coated with 70 MMT/chitosan bilayers, their oxygen permeability coefficient was reduced up to $97 \%$ (Figure 5).
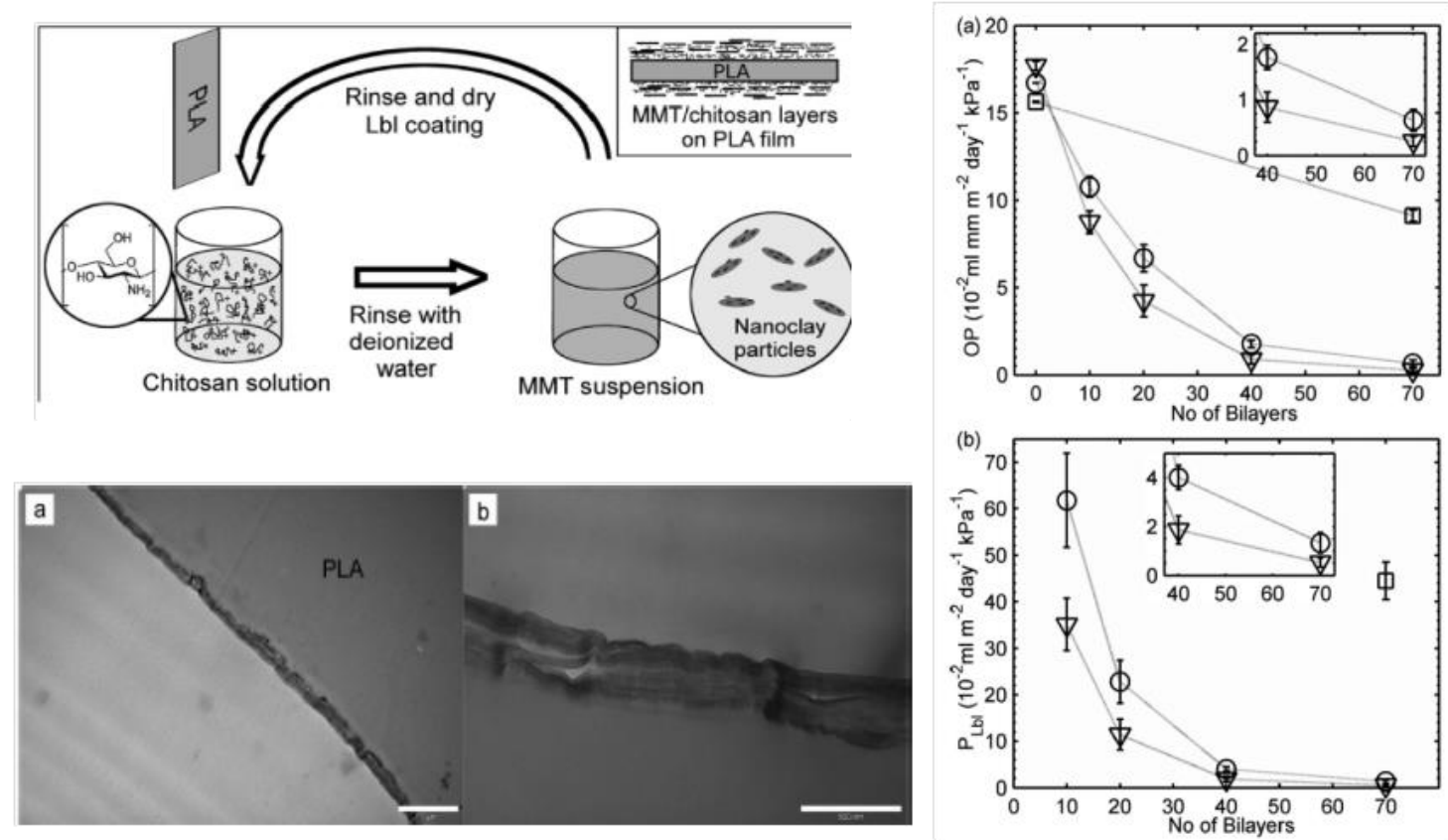

Figure 5. Schematic of the layer-by-layer deposition process (top left), TEM images showing 20 bilayers of MMT and chitosan on a PLA film (bottom left) and oxygen permeability coefficients of PLA films coated with varying numbers of MMT/chitosan bilayers obtained at 20, 50 and $80 \%$ RH. (right). Reprinted with permission from Ref. [59].

\subsubsection{Crystallisation behaviour}

An increase of the PLA crystallisation rate is of major importance for some industrial applications. The addition of nanoparticles into PLA matrix could act as nucleating agents and, hence, the effect of layered silicates on the PLA crystallisation has widely been studied. Ray et al. [50] reported the crystallisation behaviour of PLA nanocomposites using different types of layered silicates at $4 \mathrm{wt} .-\%$ and observed an enhancement of PLA crystallisation in all cases. Moreover, layered silicates generated the formation of smaller spherulites and increased the nuclei density. In the same way, Nam et al. [60] showed that the overall crystallisation rate increased for PLA/clay nanocomposites; however, the order of the spherulites was much higher for pure PLA, confirming that clays can act as nucleation agents. The same nucleating effect was observed by $\mathrm{Di}$ et al. [61] at low concentration of 
organoclays. However, an antagonist effect was reported at higher concentrations where the organoclays were described to act as physical hindrance to the PLA chain mobility, due to the strong affinity of the exfoliated clay with the polymer matrix (Figure 6). In general, PLA crystallisation form does not seem to be affected by the addition of organoclays [62].

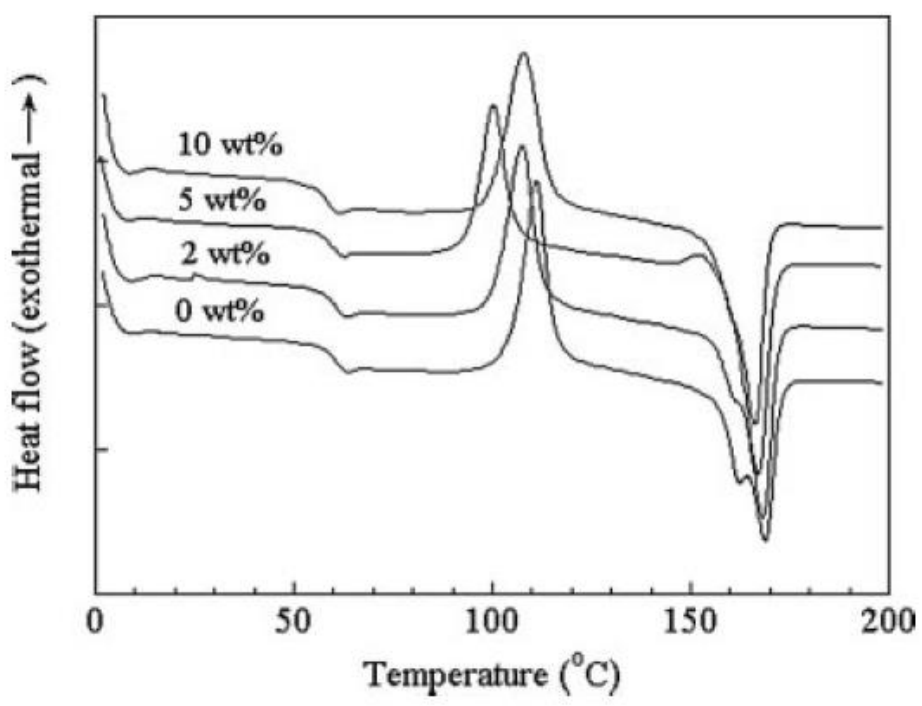

Figure 6. DSC melting thermograms of PLA and PLA/C3OB nanocomposites at different filler contents. Reprinted with permission from Ref. [61].

Bionanoparticles were also described as nucleating agents for the PLA matrix. The addition of 10 wt.-\% of MFC was reported to reduce by half the annealing time necessary to fully crystallise neat PLA [63]. Interestingly, this study also demonstrated that partially crystalline PLA/MFC composites displayed the same mechanical properties than fully crystalline neat PLA, reducing the crystallisation time by $1 / 7$.

Moreover, the modification of $\mathrm{CNC}$ and the resulting improved dispersion appear to have an important influence over their nucleation effect as reported by several research groups [6466]. The nucleating agent behaviour of unmodified and surface silylated cellulose nanocrystals in a PLLA matrix were observed by polarised optical microscopy by Pei et al. [65]. The nuclei density increased significantly with the addition of silylated CNC, due to the improved dispersion of cellulose nanocrystals in the PLLA matrix. As a result, more crystals were able to nucleate and grow on the increased surface area of the interface due to the increasing number of nucleating particles (Figure 7). The influence of PLA grafting onto CNC surface over PLA crystallisation was studied by Goffin et al. [67] The reduction of the half-time crystallisation together with the increase of crystallisation degree suggested that 
PLA-grafted-CNC also acted as nucleating agents. However, in this case, the effect of shorter PLA chains grafted or not into the PLA matrix could also influence its crystallisation.

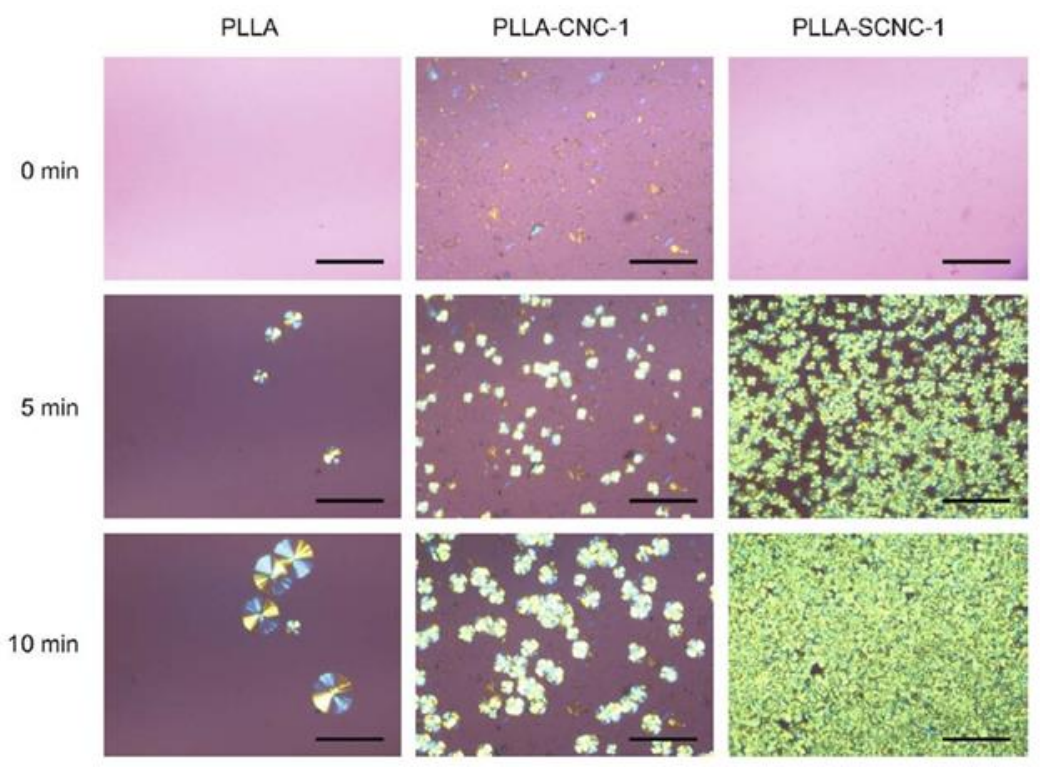

Figure 7. Polarised optical microscope images of PLLA, PLLA with 1 wt.-\% of CNC and 1wt. $-\%$ of sylilated CNC after 0, 5 and 10 min at $125^{\circ} \mathrm{C}$ crystallisation from melt. Reprinted with permission from Ref. [65].

\subsubsection{Acceleration of PLA biodegradation process}

The biodegradation in compost is a crucial issue for plastics with short service times, especially in order to reduce the amount of plastic waste disposal in landfill that reached 10.4 Mtonnes in Europe in 2010 [68]. PLA appears to be an ideal candidate for composting, as described in our introduction. Nevertheless, it is of interest to find new ways of improving and accelerating PLA biodegradation under composting conditions.

Kale et al. [12] objectively reviewed the current situation of packaging compostability and the main methods of composting the bioplastics. They also reported the different factors affecting the biodegradation rates, considering the composting conditions and the polymer characteristics. Here, we will focus on the polymer specificity. The molecular weight, crystallinity, chain flexibility and size and shape are of major importance to control the degradation rate. As an example, Kale et al. [69] compared the degradation of a PLA bottle and a PLA deli container, both being made out of commercially available PLA, under compost conditions. The PLA bottle was composed of $96 \%$ of L-lactide and presented a higher crystallinity $(12 \%)$ than the deli container (1.4\%), composed of $94 \%$ of L-lactide. On another hand, the deli container had a higher molecular weight than the PLA bottle. The 
authors reported a faster degradation rate of the container, attributed to the high crystallinity of the bottle. After 30 days of composting, the container completely disappeared, meanwhile some residues were still observed for the bottle. The molecular weight loss of the PLA container was also higher than the bottle one during the first 15 days of the experiment.

Thus, PLA properties play an important role regarding the biodegradation. Nevertheless, some additives have also been considered in order to accelerate the process. The addition of hydrophilic fillers has been reported by few authors [70, 71]. Petikanis et al. [70] blended PLA with cornstarch and wood-flour and evaluated the biodegradability by measuring the amount of $\mathrm{CO}_{2}$ collected during the composting test (AS ISO14855). They reported a slight increase of PLA biodegradation rate when adding $10 \%$ of fillers. On another hand, Matthew et al. [71] described the biodegradation in compost of PLA composites reinforced with microcrystalline cellulose, wood-flour and wood-pulp prepared by extrusion. Surprisingly, the addition of 25 wt.- $\%$ of filler reduced the disintegration rate when compared to pure PLA, this reduction being attributed to resistance to water uptake and diffusion through the composites. Among the composites, the PLA/wood-flour one displayed the fastest degradation, leading the authors to conclude that this composite was more susceptible to water.

The addition of nanoparticles has also been considered as a possible method to improve PLA biodegradation. Special attention has been attributed to PLA/clays nanocomposites. However, no clear conclusion can be drawn from the results reported so far. The presence of clays could increase the hydrophilicity of the PLA nanocomposites, depending of its superficial modification. Nevertheless, well dispersed nanometric platelets could also reduce the diffusion of water through the nanocomposites.

Some authors observed an improvement of the biodegradability, especially when the interlayer cation of the silicates possessed terminal hydroxylated groups which could start heterogeneous hydrolysis of the PLA ester group, acting as a catalyser [11, 13, 72]. Ray et al. [72] demonstrated this effect by comparing nanocomposites using two types of clays, with and without hydroxyl groups, and different dispersion degrees. It appeared that exfoliated organoclays with hydroxyl-groups gave the highest degradation rate as the PLA matrix was in contact with the clay edge and surface. Moreover, Paul et al. [13] studied the hydrolytic degradation of PLA nanocomposites in a phosphate buffer solution and observed that the fastest hydrolysis was reported for the unmodified MMT. They also concluded that the more hydrophilic the clay, the more pronounced was the degradation. Additionally, Fukushima et 
al. [11] confirmed that the dispersion and the presence of hydroxyl group of the clay appeared to play an important role over the hydrolytic degradation and biodegradation rate.

Meanwhile, other researchers have observed a delayed biodegradability due to a counterbalanced effect caused by the improved barrier properties of the materials, which could hinder the microorganism diffusion through the bulk [73]. Fukushima et al. [74] also observed a reduction of the degradation rate of PLA when adding a $5 \mathrm{wt} .-\%$ of an unmodified sepiolite and attributed this effect to the chain mobility reduction due to polymer-silicate interactions. Furthermore, some authors have reported an antimicrobial activity of the organoclays due to their quaternary ammonium group and it was demonstrated by toxicity experiments that modified montmorillonite could delay the microbial degradation of PLA by bacteria responsible of its biodegradation in compost $[11,37,75]$.

\subsubsection{Thermal stability}

The thermal stability and degradation profiles of materials are usually assessed by thermogravimetric analysis (TGA). TGA of the PLA matrix under inert atmosphere exhibits a typical single weight-loss step, with a maximum decomposition rate at about $370{ }^{\circ} \mathrm{C}$. In general, layer silicates have been reported to increase the thermal degradation temperature of PLA. The silicate layers act as a barrier for incoming gases as well as for gaseous by-products formed during degradation, improving the thermal stability of the materials [48]. The extent of this increase usually depends on the exfoliation degree of the organoclays [76].

It is more complicated to make general statements about the thermal degradation of PLA/bioparticle nanocomposites. The effect over the degradation temperature strongly depends on the properties of the filler, which in turn depend on the extraction source and hydrolysis conditions. No real influence was observed regarding the addition of cellulose nanowhisker [55, 64]. Nevertheless, the outstanding performances of bacterial cellulose fibres associated to their high crystallinity and purity generate higher thermal stability of the resulting nanocomposites, as reported by Lee et al. [77]. They observed an increase of the nanocomposite degradation temperature of $20{ }^{\circ} \mathrm{C}$ after the addition of 5 wt.- $\%$ of bacterial cellulose. Likewise, Tomé et al. [78] reported a slight increase of $6^{\circ} \mathrm{C}$ of the nanocomposite thermal degradation temperature with the addition of $6 \mathrm{wt} .-\%$ of bacterial cellulose nanofibres and of $15^{\circ} \mathrm{C}$ with acetylated nanofibres. 


\subsubsection{Transparency}

Transparent matrices, such as PLA, should retain their transparency with no reduction of the amount of light transmitted when a low volume percentage of well dispersed nanoreinforcement are added. Thus, the transparency of nanocomposites is also an indication of the nanofiller dispersion. Pluta et al. [79] observed that some opacity was obtained for a microcomposite based on unmodified clay while organoclay nanocomposites displayed higher transparency. Unmodified clays are expected to present a particle size comparable to the light wavelength. Nevertheless, Sanchez-Garcia et al. [80] reported a brownish colour for the clay nanocomposites and a gradual increase of yellowness index with increasing filler contents. A reduction of $32 \%$ of visible light transmitted (at $650 \mathrm{~nm}$ ) was also observed when added 5 wt.-\% of clays. Peterson et al. [81] compared the optical properties of bentonite and swollen microcrystalline cellulose nanocomposites. Poor light transmission indicated that exfoliation was not achieved (Figure 8).
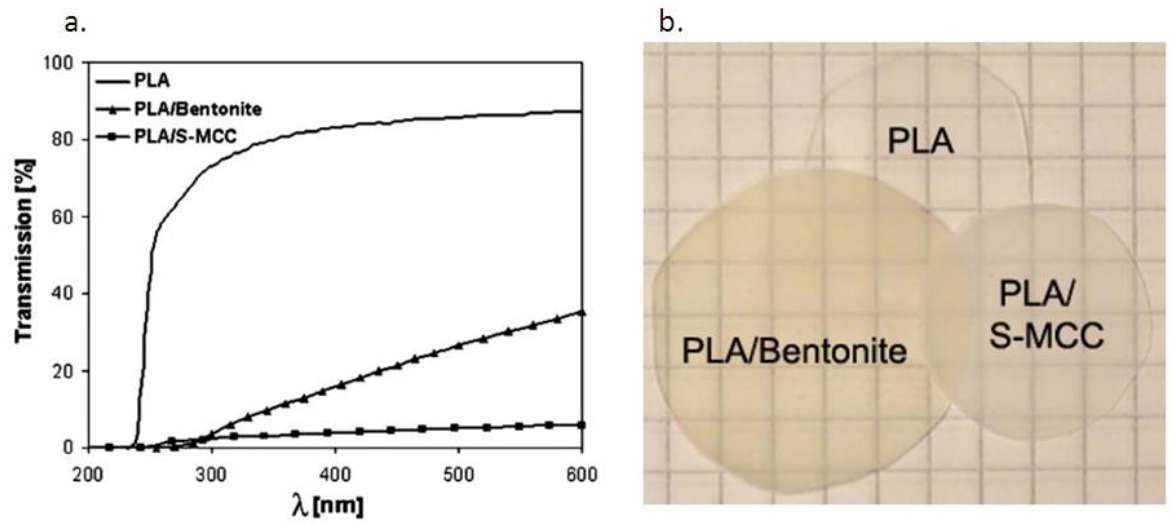

Figure 8. (a) Transparency measurement of PLA, PLA/bentonite and PLA/microcrystalline cellulose. Reprinted with permission from Ref. [148].

On the other hand, good transparency was obtained with well dispersed modified cellulose nanocrystals in the PLA matrix, as observed by Fortunati et al. [64] and Sanchez-Garcia et al. $[55]$.

\subsubsection{Synergetic improvement of PLA properties}

In view of the excellent results obtained with PLA bionanocomposites, some authors tried to combine the effect of toughening additives with nanoparticles with the objective of preparing toughen PLA materials with improved properties. As an example, Thellen et al. [82] 
combined a plasticiser (citrate ester) and montmorillonites (MMT) to produce PLA blown films. However, the plasticiser acted more as a processing aid than a toughening agent as the elongation at break of the materials remained below $10 \%$. Interestingly, a $48 \%$ improvement of oxygen barrier was reported for the film containing 5 wt.- $\%$ of clays, probably due to orientation of the clays during the blowing process. Martino et al. [83] combined the effect of 15 wt.-\% of polymeric adipates and 3 wt.-\% of organoclays (C30B). When the organoclays were previously mixed with low molecular weight liquid polyadipates, swelling occurred and eased the further intercalation of PLA chains into C30B galleries. The addition of 15 wt.- $\%$ of polyadipate led to an increase of the elongation at break of up to $300 \%$. A loss of ductility was observed with the addition of 3 wt.- $\%$ of C30B but the elongation at break still remained above $200 \%$. A slight increase of modulus was observed while the oxygen transmission rate was reduced of about $25 \%$.plasticiser.

Plasticised PLA/MMT with poly(ethylene glycol) has been reported by several authors [62, 75, 84-86]. Paul et al. [84] studied the effect of the addition of four types of organoclays on PLA plasticised with 20 wt.-\% of PEG 1000. It appeared that both PLA and PEG were able to intercalate in the clay galleries, depending on the clay modifications. Intercalated nanocomposites were obtained even for unmodified MMT due to the interlayer migration of PEG. Two other studies of the same authors reported in detail the properties of the systems $[62,85]$. Plasticisation reduced the PLA $T_{g}$ by $26^{\circ} \mathrm{C}$ for unfilled sample and by about $21{ }^{\circ} \mathrm{C}$ after the addition of the nanoclays. An increase in thermal stability with the clay content up to loading of 5 wt.- $\%$ in clay was observed. The dynamic mechanical properties were also analysed and two peaks were observed in the loss modulus attributed to PLA and PEG rich phase. Moreover, PEG acted as a reinforcement below its glass temperature and the storage modulus also gradually increased with the filler content. However, the blends appeared to be unstable over time as PEG diffusion towards the surface was observed $[62,85]$. No tensile or impact mechanical properties were reported in these studies. Nevertheless, Tanoue et al. [86] observed that the addition of PEG to the PLA/MMT blend resulted in more agglomerated structures and the elongation at break of the materials remained below $5 \%$. In addition, the shear-thinning properties of the nanocomposites are independent of the addition of PEG.

Copolymers have also been used for such system, as reported by Paul et al. [84]. They synthesised P(L,L-LA-b-EG-b-L,L-LA) triblock copolymers by in-situ polymerisation in presence of $\mathrm{C} 30 \mathrm{~B}$. They reported intensive exfoliation of the clays and the $T_{g}$ of the nanocomposites decreased from $60{ }^{\circ} \mathrm{C}$ to $12{ }^{\circ} \mathrm{C}$ for a PEG content of 16.2 wt.-\%. Moreover, 
the thermal stability of the nanocomposites decreased as the polyether level increased within the triblock copolymer. This method could be a good solution to avoid PEG migration.

Finally, blending PLA with other polymers and nanofillers has also attracted the interest of researchers as it has been demonstrated that immiscible polymer blends could be stabilised and compatibilised by nanoparticles [54, 87-92]. Chen et al. [87] reported the properties of nanocomposites based on PLLA/PBS blends. A twice functionalised organoclay (TFC) containing epoxy groups prepared from a commercial organoclay (C25A) was used in this study. At low contents, TFC was exfoliated and located in the PLA phase. When the concentration was increased to 5 and $10 \mathrm{wt} .-\%$, intercalated/exfoliated clays were observed in both PLA and PBS phase. PBS domains gradually decreased with the addition of TFC. The addition of $10 \mathrm{wt} . \%$ of TFC into the PLLA/PBS blend led to better mechanical properties, as the Young's modulus increased from 1100 to $2000 \mathrm{MPa}$ and the elongation at break from 70 $\%$ to $120 \%$ when compared to the simple blend. Simultaneous increase of modulus and elongation at break was attributed to the chemical bonds formed between TFC and both polymers. Chen et al. [88] reported that the incorporation of TFC in poly(lactic acid)/poly[(butylene succinate)-co-adipate] PLLA/PBSA blends, led to an increase of the elongation at break as well as tensile modulus and yield strength in relation to PLLA/PBSA/C25A nanocomposite. In addition, PLLA/PBSA/TFC began to be degraded at higher temperatures. This results of the higher degree of exfoliation of the clay platelets due to an increased interfacial adhesion.

Ojijo et al. [89] studied the morphology and properties of PLA/PBSA/MMT 70/30/6 composites using four types of organoclays. It appeared that the morphology of the blend was strongly influenced by the clay addition, the PBSA domain size being strongly reduced, depending on the clay interlayer spacing and interaction with both polymers. The smallest domain size was reported for the commercial organoclay Cloisite C20A. Nevertheless, the mechanical properties showed that no improvement of elongation at break was achieved for these blends, probably due to the crystallinity of the blends.

PLA/PCL/MMT nanocomposites were described by Hasook et al. [90]. They reported an increase of Young's modulus and tensile strength with respect to neat PLA for PLA/PCL/MMT 90/5/5. However, the elongation at break always remained below $4 \%$. On the other hand, the thermal stability of the PLA/clay nanocomposites was slightly increased with the addition of PCL. Sabet et al. [91] premixed an organoclay with maleated polypropylene to improve its compatibility with both polymers. The clay content was 3 wt.-\% 
in a PLA/PCL 80/20 blend, obtaining a better exfoliation when using the maleated polypropylene (in a ratio of 3:1 with the clay). A reduction of PCL dispersed domain and a decrease of $\mathrm{O}_{2}$ permeability was observed with the addition of the clays. Nevertheless, the mechanical properties were not evaluated.

Arroyo et al. [92] also reported the preparation of PLA/TPS/MMT composites using unmodified clays. The addition of clay increased the tensile modulus of the materials, in particular, in TPS rich blends. However, the fracture toughness and elongation at break decreased by the addition of the clay. The authors postulated that the clay preferentially located at the blends interface could reduce the interaction between both polymer phases in compatibilised blends though the use of maleic anhydride. This resulted in a lower stress transfer from PLA to the TPS dispersed phase. In addition, the addition of the clay led to a slight increase in PLA non-isothermal crystallisation.

Bitinis et al. [54] developed a novel toughened poly(lactic acid) bionanocomposite with tuneable properties successfully prepared by melt mixing PLA with natural rubber and several montmorillonites. The organoclays, $\mathrm{C} 15 \mathrm{~A}$ and $\mathrm{C} 30 \mathrm{~B}$ were preferentially located at the interface acting as compatibilisers between both polymer phases, forming a solid barrier and preventing the coalescence of NR droplets. This location resulted in a marked improvement of the physical and mechanical properties of the system. Moreover, these properties were controlled as a function of the nanofiller surface properties and the mixing procedure used. So, while C30B produced stiffer materials due to its better compatibility with PLA, a further increase of the elongation at break of the PLA/NR blend was observed by the addition of low C15A contents in the nanocomposite. This particular behaviour was further studied analysing the micromechanical deformation mechanisms of bionanocomposites during uniaxial stretching by using simultaneous synchrotron SAXS and WAXS techniques (Figure 9) [93]. PLA/NR blend is a ductile material in which debonding associated to the formation of voids occurs when stretching, while PLA/NR/C15A bionanocomposites upon deformation exhibit crazes formation. The organoclay preferentially located at the PLA/NR interface acts as compatibilising agent hindering the formation of voids between the two polymer phases and favouring the generation of a large number of crazes in PLA/NR blend that are able to develop higher deformations This mechanism allows under elongation a progressive orientation of polymer chains, nanoparticles and interfaces. 

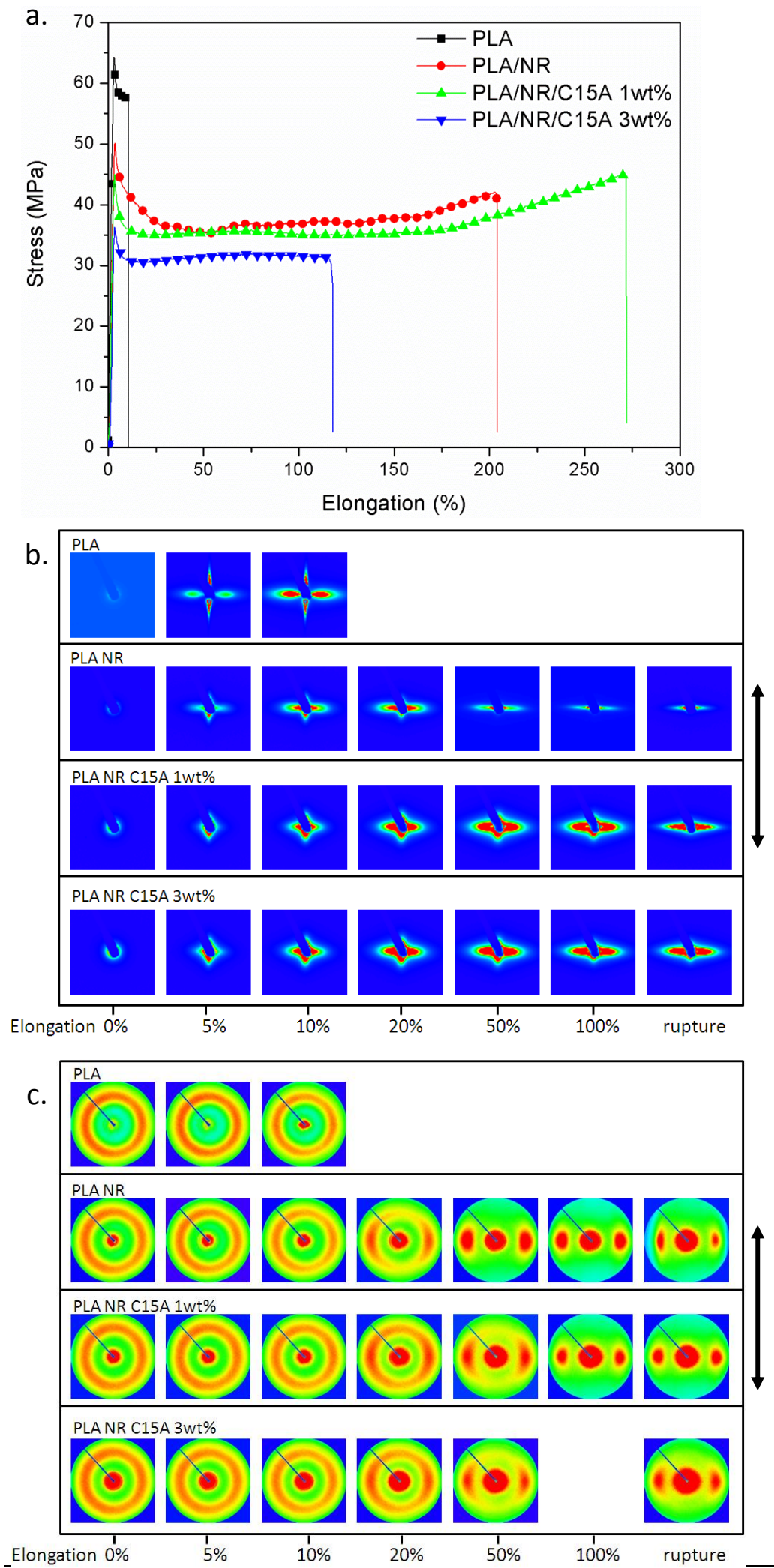

Figure 9. (a) Mechanical properties of the PLA/NR blend and its nanocomposites. The pictures present in- situ simultaneous (b) SAXS patterns and (c) WAXS patterns at selected elongation values. The arrows indicate the stretching direction. Reprinted with permission from Ref. [93]. 
It appears that $1 \mathrm{wt} .-\%$ of organoclay is the optimum concentration in this blend regarding the mechanical properties. Higher organoclay concentration precludes craze development and their transformation into cracks results in the sample mechanical failure. Moreover, in this study, the authors demonstrated that the addition of the organoclay C15A to the PLA inhibited the crazes formation favouring the cavitation, probably at the interface between the organoclay and the matrix. Therefore, they concluded that the reason for crazing mechanisms in the PLA/NR/C15A bionanocomposite is the existence of a synergy effect obtained by the addition of rubber phase and right amount of the nanofillers.

Fortunati et al. [64, 94] produced PLA based high performance composites for packaging applications using an innovative combination of cellulose nanocrystals (CNC) and silver nanoparticles $(\mathrm{Ag})$ in order to obtain multifunctional systems. CNC have attracted significant attention during the last decade as potential nanoreinforcement in different polymers due to their high aspect ratio and a large surface area (ca. $150 \mathrm{~m}^{2} / \mathrm{g}$ ). Moreover, cellulose nanocrystals have better mechanical properties than a majority of the commonly used reinforcing materials and offer additional exceptional advantages such as biodegradability and biocompatibility, high stiffness and low density. The authors prepared binary and ternary nanocomposites with increased mechanical and thermal properties due to cellulose introduction, providing an antimicrobial response with the silver nanoparticles. CNC were synthesised from commercial microcrystalline cellulose by sulphuric acid hydrolysis and the hypothesis to modify crystal surface with surfactant as a means to improve the dispersion of filler in PLA matrix was successfully confirmed. The presence of surfactant on the nanocrystal surface favours the dispersion of the nanocellulose in the PLA matrix and the nucleation effect was remarkably enhanced highlighting the effect of the crystals and of their surface modification on the thermal and mechanical properties of the nanocomposites. A bactericidal effect of nanocomposites on Stapylococcus aureus and Escherichia coli was detected suggesting that these systems can offer good perspectives for food packaging and sanitary applications which requires an antibacterial effect constant over time.

Finally, the introduction of plant fibres as reinforcement in biodegradable polymer matrices may contribute to improving their mechanical properties, making them more suitable to the use in semi-structural components. Fortunati et al. [95] combined PLA matrix with phormium fibres highlighting that natural fibres are suitable for polymer reinforcement while the disintegrability in composting conditions of PLA composites was studied in order to gain insights into the post-use degradation processes. 


\section{PLA in Tissue Engineering: Nanoparticles, nanocomposites and nanotopography}

Biomaterials play a critical role in the success of tissue engineering as they guide the shape and structure of developing tissues, provide mechanical stability and offer opportunities to deliver inductive molecules to transplanted or migrating cells. They have to provide informative micro environments allowing cells to interpret the biomaterial instructions and modify their behaviour accordingly [96]. In particular based on its composition and structure, biomaterials will transmit specific signals to cells that will decode into biochemical signals. Hence, topography [97-101], chemistry and physical properties [102-106] of biomaterials are critical parameters for directing cell fate [107]. Since natural tissues, organs or cells have a nanometer structure, the biomimetic features and excellent physicochemical properties of nanomaterials play a key role in stimulating cell growth as well as guide tissue regeneration [108].

Recently, nanostructured biomaterials having physical nano-features such as nanocrystals, nanofibres, nanosurfaces, nanocomposites, etc. gained much interest in regenerative medicine [109]. This is mainly because of their resemblance of physical nano-features to natural extra cellular matrices (ECM). It has been recognised that nanoscale and molecular level design of surfaces is essential to the development of new biomaterials able to recognise specific surface signals. Nanotechnology, or the use of nanomaterials can mimic surface properties of natural tissues. For these reasons, over the last decade, nanomaterials have been highlighted as promising candidates for improving traditional tissue engineering materials [108]. Using nanotechnology for regenerative medicine becomes obvious when examining nature. In this new era of nanotechnology attempts are to be made for making use of nanostructured materials for a wide range of properties in tissue targeting and controlling drug release [110$115]$.

Curtis and Wilkinson [116] indicated that the nano-world is totally different from the macroscopic community, which consider that materials can be scaled down through orders of magnitude to the microscopic scale with little or no change in expected properties. In the nano-world, interfacial forces become of great importance and quantization effects emerge as well. Evidences are increasingly accumulating that cells may respond to a nanometric environment as similar to natural.

The synergism of nanotechnology and biodegradable polymers promises to have a profound impact on stem cell based clinical applications for tissue regeneration. To date, numerous top- 
down and bottom-up nanofabrication technologies (such as electrospinning, phase separation, self-assembly processes, thin film deposition, chemical vapour deposition, chemical etching, nano-imprinting, photolithography, and electron beam or nanosphere lithographies) are available to synthesize nanomaterials with ordered or random nanotopographies (Figure 10) [97-100, 111, 117-121]. After decreasing material size into the nanoscale, dramatically increases surface area, surface roughness and surface area to volume ratios can be then created to lead to superior physiochemical properties (i.e., mechanical, electrical, optical, catalytic, magnetic properties, etc.).

In recent decades, nanotechnology has been widely applied to polymeric materials, with the ultimate goal of dramatically enhanced performance [122-126]. There are two main approaches to achieve polymeric nanomaterials. The most popular is to introduce nanoscale particles into a polymer matrix to produce polymer/nanoparticle nanocomposites. The other is to fabricate polymer materials structured themselves on the nanoscale.
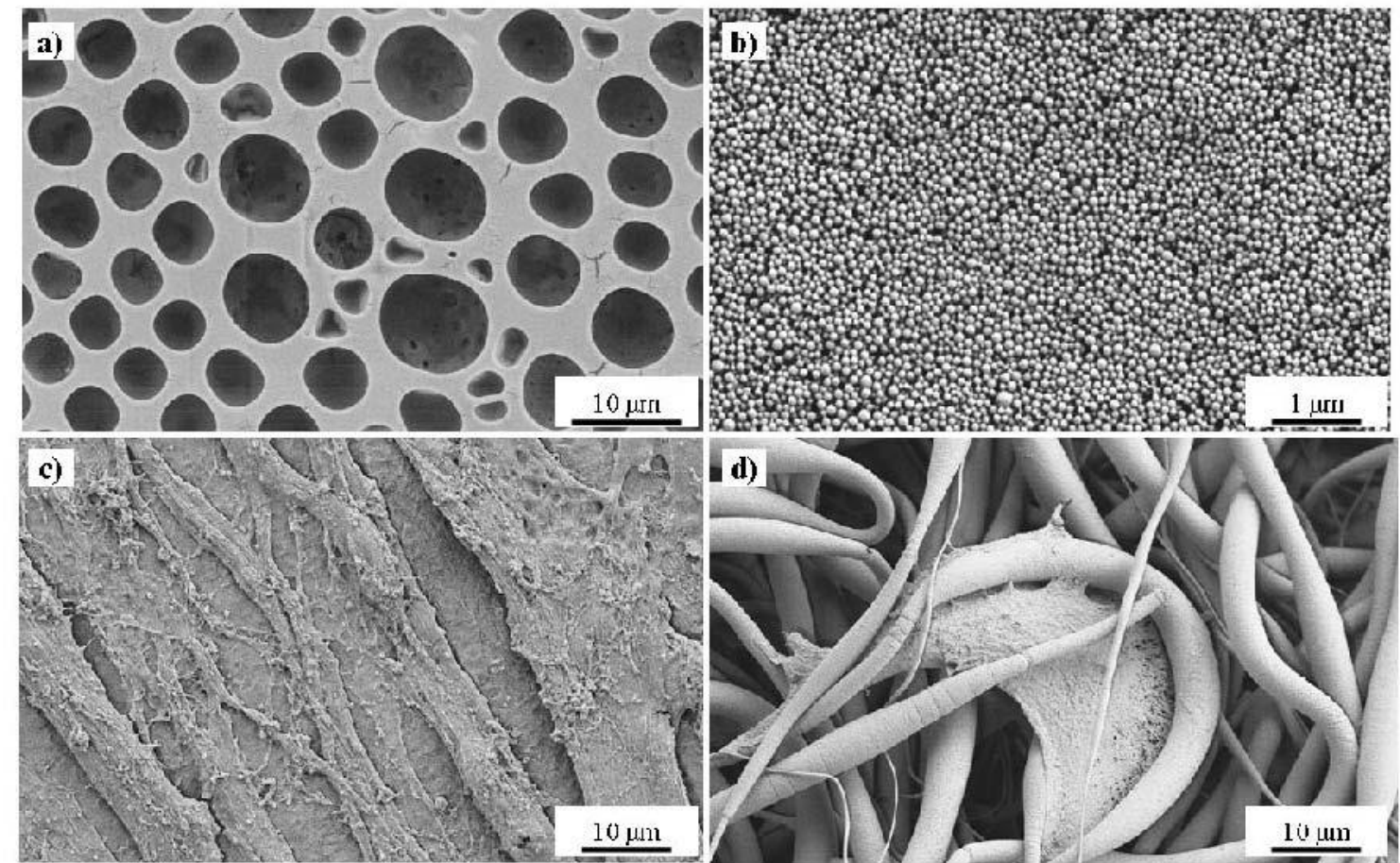

Figure 10. Electron microscopy images of porous PLLA film (a), PLLA nanoparticles (b), interaction between osteoblasts and PLLA based nanocomposite films (c) [127], and interaction between stem cells and PLLA based nanocomposite electrospun membranes $(d)$ [128]. Reprinted with permission from Refs. [127] and [128] 


\subsection{Nanoparticles}

The term nanoparticles in tissue engineering defines particulate dispersions or solid particles with a range of 10-1000 $\mathrm{nm}$ and with the bioactive molecule dissolved, entrapped, encapsulated or attached to the matrix of the nanoparticle itself [110]. Polymeric nanoparticles present a highly attractive platform for a wide array of biological applications. The surface and core properties of these systems can be engineered for individual and multimodal applications, including tissue engineering, therapeutic delivery, biosensing and bioimaging $[112,129]$. Nanoparticles in drug delivery systems, due to their diminutive size, can penetrate across barriers through small capillaries into individual cells to allow efficient drug accumulation at the targeted locations in the body [113, 129-132]. Figure 11 shows a schematic view and transmission electron microscopy images of nanospheres and nanoshells based on PLA polymer matrix.

The precise control of size and shape in micro/nano-fabrication has promoted a paradigm shift in the systemic administration of particulate systems for biomedical applications: both geometry and surface physico-chemical properties contribute substantially to the optimal design of the particulate system. Geometry affects the transport and biodistribution of the particles, at the vascular level, the strength of adhesion and the internalisation rate at the cellular level, favouring particle accumulation in proximity of the blood vessels (margination dynamics). Size and shape influence also the strength of adhesion to cells improving target specificity and influences the rate of internalisation discriminating between particles for nuclear delivery (rapid internalisation) and particles for vascular targeting (no internalisation) [88]. 


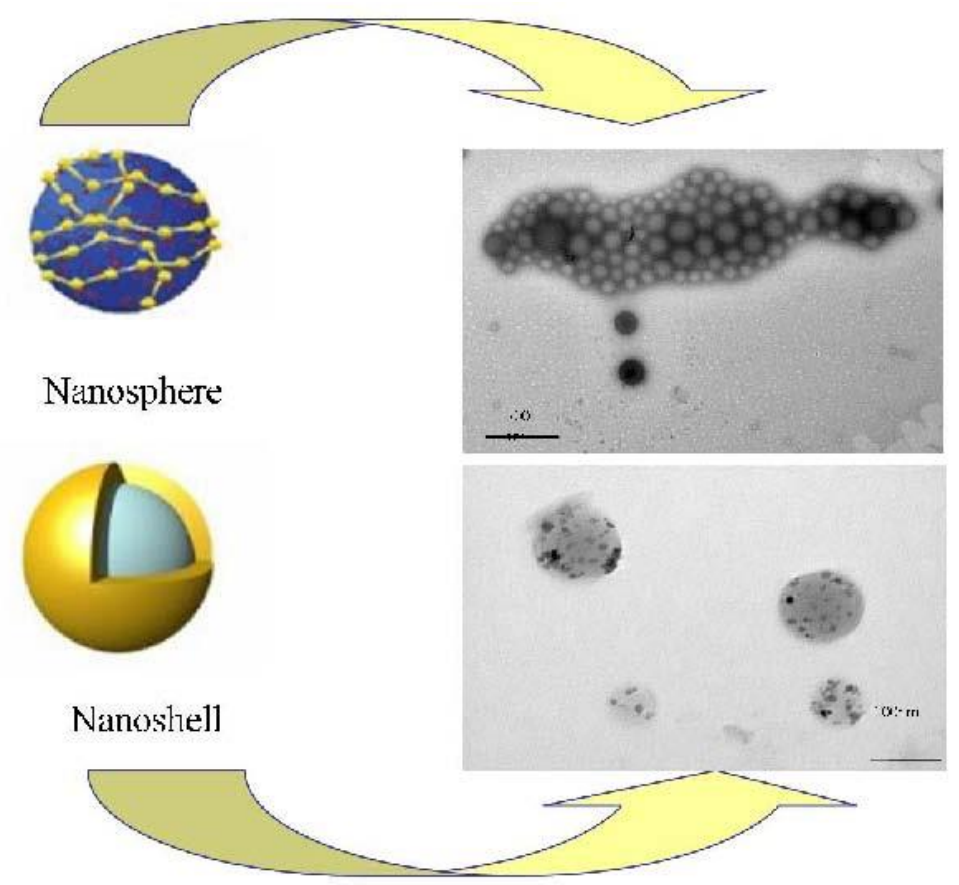

Figure 11. Scheme of nanosphere and nanoshell structure with transmission electron microscopy images.

Biodegradable nanoparticles are frequently used to improve the therapeutic value of various water soluble/insoluble medicinal drugs and bioactive molecules by improving bioavailability, solubility and retention time [132]. The use of nanoparticle based drug formulations reduces the patient expenses and risks of toxicity [107], offering many advantages in terms of protection of premature degradation and interaction with the biological environment, enhancement of absorption into a selected tissue, bioavailability, retention time and improvement of intracellular penetration [133]. The major goals in designing nanoparticles as a delivery system are to control particle size, surface properties, loading and release of pharmacologically active agents so as to achieve the site specific action of the drug at the rationale rate and dose.

\subsubsection{Preparation of nanoparticles}

Polymeric nanoparticles have been synthesised using various methods [110, 114, 134-136] according to needs of application and type of drugs to be encapsulated. The selected method determines the characteristics of spheres, including the size as the most important property because it is strongly related to the administration mode [115, 137, 138]. Another property influenced by the preparation process is the ability to interact with active principles contained 
in the drugs formulation. The most common method based on dispersion of preformed polymers is the emulsification-solvent evaporation technique. This technique has been successful also for encapsulating hydrophobic drugs. Briefly, solvent evaporation is carried out by dissolving the polymer and the compound in an organic solvent. Frequently, dichloromethane or methylene chloride is used for PLA and their copolymers. The emulsion is prepared by adding water and a surfactant to the polymer solution. In many cases, the nanosized polymer droplets are induced by sonication or homogenisation. The organic solvent is then evaporated and the nanoparticles are usually collected by centrifugation and lyophilisation [134, 139-142]. A modification on this procedure has led to the protocol preferred for encapsulating hydrophilic compounds and proteins, the double or multiple emulsion technique. First, a hydrophilic drug and a stabiliser are dissolved in water. The primary emulsion is prepared by dispersing the aqueous phase into an organic solvent containing a dissolved polymer. This is then re-emulsified in an outer aqueous phase also containing stabiliser $[115,137,138,143,144]$. From here, the procedure for obtaining the nanoparticles is similar to the single emulsion technique for solvent removal. The method of nanoprecipitation is based on the interfacial precipitation of polymers following displacement of a semi-polar solvent miscible with water from a lipophilic solution [133]. It constitutes an easy and reproducible technique that has been widely used in the preparation of poly(lactic acid) and poly(lactic-co-glycolic acid) (PLGA) based nanoparticles [145-148]. One alternative to the widely applied emulsion and nanoprecipitation procedures is the salting-out method. This method involves the use of a solution including the polymer and, eventually, the drug in a water-miscible solvent such as acetone or tetrahydrofuran. The solution is emulsified under vigorous stirring in an aqueous gel containing the salting-out agent and, if required, a stabiliser [149-151]. Another way to obtain nano-and micro-spheres is the spraydrying method where the drug is solubilised or dispersed in an organic solution of the polymer that is then nebulised in a hot-air flow. The solvent is instantaneously evaporated and dried nano- and micro-particles are finally recovered. This method seems to be more versatile, compared with the methods previously described, considering the solubility parameters of the polymer and the drug point of view [152-154].

\subsubsection{Nanoparticle properties}

Biodegradable nanoparticles (NPs) have been used frequently as vehicles due to its grand bioavailability, better encapsulation, control release and less toxic properties. Particle size and 
size distribution are the most important characteristics determining the fate of nanoparticle systems including biological activity, toxicity and the targeting ability of nanoparticle systems in vivo. Drug loading, drug release and stability of nanoparticles are also influenced by particle size and size distribution [136, 155]. Many studies have demonstrated that particles of sub-micron size have a number of advantages over micro particles as a drug delivery system $[156,157]$. Nanoparticles have in general relatively higher intracellular uptake compared to microparticles. Polymer degradation can also be affected by the particle size [158]. Size reduction can modify the physical and chemical properties of bionanomaterials distinctively from their bulk and molecular counterparts. Thanks to their nano-size the particles can be endocytosed/phagocytosed, enhancing cell internalisation of the drug and leading to drug delivering closer to the intracellular site of action [159]. The main advantages offered by polymeric nanoparticles are the possibility to carry the drug molecules, to protect drug degradation, and to control drug release over prolonged time periods [107].

In a previous study we developed a promising approach to produce small, spherical and highly uniform polymeric biodegradable and porous nanoparticles by double emulsion method [160]. PLGA and PLLA nanoparticles were developed with an average diameter of $180 \mathrm{~nm}$ for PLLA and $218 \mathrm{~nm}$ for PLGA nanoparticles. The nanoporous structure of the NPs, investigated by a thermoporosimetry method, underlining a pore diameter of $16 \mathrm{~nm}$ on the NP surface, the presence of this nanoporous structure could have important implications in the kinetic of drug release.

\subsubsection{Drug loading and drug release mechanisms}

Nanoparticles, nanospheres, or nanocapsules can be constructed to possess different properties and release characteristics for the best delivery or encapsulation of the therapeutic agent [161]. Polymeric nanoparticles can be tailor-made to achieve both controlled drug release and disease specific localisation by tuning the polymer characteristics and surface chemistry [166]. The molecular weight, the drug polymer interaction and the presence of end functional groups (ester or carboxyl) are the factors which determine drug loading and entrapment efficiency [110]. These systems in general can be used to provide targeted (cellular or tissue) delivery of drugs, improve bioavailability, sustain release of drugs or solubilise drugs for systemic delivery [161]. These nanoparticles formulated from PLGA and PLA have been developed for sustained drug delivery and are especially effective for drugs with an intracellular target and have been adopted as a preferred method for nanomaterial 
drug delivery [162]. They also exhibit a good potential for surface modification via chemical transformations, provide excellent pharmacokinetic control and are suitable for the entrapment and delivery of a wide range of therapeutic agents [162]. Because nanoparticles are colloidal systems, precise determination of the drug content is a major problem. Therefore, the most reliable way to separate the nanoparticles from the solution containing unbound drug is ultracentrifugation or gel filtration.

Drug release mechanisms are equally important as drug loading. For developing successful nanoparticulated systems, both drug release and polymer biodegradation are important factors [163]. Nanoparticle porosity is an important parameter to correlate to different NP formulations and release rate [164].

\subsubsection{Nanoparticles and cell interaction}

Polymeric nanoparticles have been applied in gene therapy of breast cancer cells, resulting in antiproliferative effects [165]. The uptake of poly(L-lactide) particles was hardly influenced by the molecular weight of the polymer. Even so, a consistent correlation between z-potential or particle size and cellular uptake could not be detected. Within the series of polymeric nanoparticles the PLGA NPs show a higher amount of uptake in the cells. In contrast, the surfactant located on the nanoparticle surface influences the cellular uptake.

In most cases anionically stabilised sodium dodecylsulfate (SDS) particle variants were taken up to a greater extent than Lutensol AT50 analogues (nonionically stabilized). The effect was most pronounced for PLLA particle uptake, whereas it was much weaker for PLGA and PCL particle uptake [166]. The most important property for polymeric nanoparticles is the surface structure which is a vital component for their targeting characteristics. Since nanoparticles come into direct contact with cellular membranes, their surface properties may determine the mechanism of internalisation and intracellular localisation [162].

Recently, focus has been placed on nanoparticles as potential non-viral vehicles for specific gene delivery [167]. In particular, nanoparticles for gene delivery can be simply fabricated by conjugating DNA onto the particle surface. These particles can easily be introduced into the cell by endocytosis. Bio-conjugated methods formed by the coating of cationic macromolecules onto the particles have been employed for increasing the specific gene complexing ability by regulation of cationic macromolecules coated onto the nanoparticles to optimize delivery of genes [168, 169]. In a recent study, PLGA nanoparticles modified with a polyplexed poly(ethylenimine), PEI/DNA coating were tested using gene expression to 
induce differentiated chondrocyte from human mesenchymal stem cells (hMSCs) [170]. This research reveals that PLGA nanoparticles are a potential tool to deliver genes that does not depend on viral vectors. These vehicles provide a useful gene transduction tool, in fact SOX9 genes were shown to increase the transfection efficacy into human mesenchymal stem cells for chondrogenesis [170].

\subsection{Nanocomposite concepts in the biomedical field}

In the large field of nanotechnology, polymer matrix based nanocomposites have become a prominent area of current re-search and development for biomedical applications [138, 171178]. For example, the selection of the appropriate biomaterial for scaffolds can have a profound impact on the quality of newly formed tissue. Given that few biomaterials possess all the necessary characteristics to perform ideally, engineers and clinicians alike have pursued the development of hybrid or composite biomaterials to synergize the beneficial properties of multiple materials. The combination of biodegradable polymers with nanostructured materials, which includes the use of nanoparticles, nanofibres and other nanoscaled features, has demonstrated the ability to enhance cellular interaction, encourage integration into host tissue, and provide tuneable material properties and degradation kinetics. Materials with nanometre-scaled dimensions, also known as nanophase or nanostructured materials, can be used to produce nanometer features on the surface of three dimensional substrates for scaffolds [172, 173]. Development of nanocomposite scaffolds materials is attractive as advantageous properties of two or more types of materials can be combined to suit better the mechanical and physiological demands of the host tissue. By taking advantage of the formability of polymers and including controlled volume fractions of a reinforcement phase, properties enhancement of the fabricated scaffold can be achieved [102, 103, 173, 174].

Polymer composite materials have been also developed for mineralised tissue engineering applications and, in this context, PLA based nanostructured biomaterials have found specific application such as prosthetic devices, implants, vascular grafts, catheters, sutures and ligament repair materials because of degradation behaviour, mechanical and biological performance, and appropriate morphology [104, 179]. Recent developments in biomedical materials have led to the creation of a variety of possible bone substitutes that possess high potential for the regeneration of skeletal defects. At the centre of these developments is the emergence of bioactive ceramics, such as calcium phosphates (hydroxyapatite and tricalcium 
phosphate) and silica-based bioactive glasses (melt-derived and sol-gel processed), which have reached the stage of clinical applications [96, 180]. Biomedical nanocomposites constituted of a bioactive ceramic and resorbable polymers have shown promise for the successful regeneration of bone tissues. Kim et al. [181] developed a novel nanocomposite made up of a bioactive glass and PLA in a nanofibrous form, generated via electrospinning. The nanocomposites showed an internal morphology of uniformly dispersed nanofibres within the PLA matrix. The nanocomposites induced rapid formation of a hydroxycarbonate apatite layer on the fibre surface under a simulated physiological medium. Osteoblasts attached and grew well on the nanocomposites and secreted collagen protein at initial culturing periods. The differentiation of cells, as assessed by the expression of alkaline phosphatase, was significantly improved on the nanocomposites as compared to those on pure PLA. Moreover, the mineralised product by the cells was observed to be significantly higher on the nanocomposites with respect to pure polymer. If biodegradability and bioactivity are to be combined in an optimised tissue engineering scaffold, then the design of nanocomposite materials offers an exceptional opportunity, allowing the creation of bioresorbable and bioactive scaffolds with tailored physical and mechanical properties [182]. Roether et al. [183] developed bioactive and bioresorbable polymers based on three-dimensional, macroporous poly(D,L)-lactic acid foams and Bioglass particles. In vitro studies in simulated body fluid (SBF) were performed to study the formation of hydroxyapatite (HAP) on the surface of PDLLA/Bioglass composites. The authors found that a thin coating of HAP was developed after 7 days in SBF, which further grew to form a thick $(10 \mu \mathrm{m})$ and uniform HAP layer on the scaffold with increasing time in SBF highlighting a new way for the development of porous bioresorbable scaffolds of high bioactivity for hard and soft tissue engineering. In another approach, nano-sized hydroxyapatite (n-HAP) has been compounded with synthetic polymers or natural macromolecules to fabricate nanocomposite scaffolds [110]. Hydroxyapatite, a major constituent of hard tissue, exhibits undesirable mechanical properties if employed alone. Thus polymer-based HAP composites are desired. Nano-HAP introduction have not only improved the mechanical properties of the polymer matrix, but also significantly enhanced protein adsorption over micro-sized HAP. Enhanced protein adsorption improves cell adhesion and function [96]. Ma et al. [184] prepared highly porous PLLA and PLLA/HAP composite scaffolds with a thermally induced phase separation technique. The mechanical properties of the nanocomposites were significantly higher than those of the pure polymer. Moreover, the nanocomposite scaffolds have been shown to have the higher osteoblast survival rate, more uniform cell distribution and growth and enhanced 
cell bone-specific gene expression in vitro. Bianco et al. [185] reported the fabrication of electrospun poly(L-lactic acid)/Ca-deficient-hydroxyapatite (PLLA/d-HAP) mats, suggesting these mats can be regarded as potential scaffolds for bone marrow mesenchymal stem cells culture.
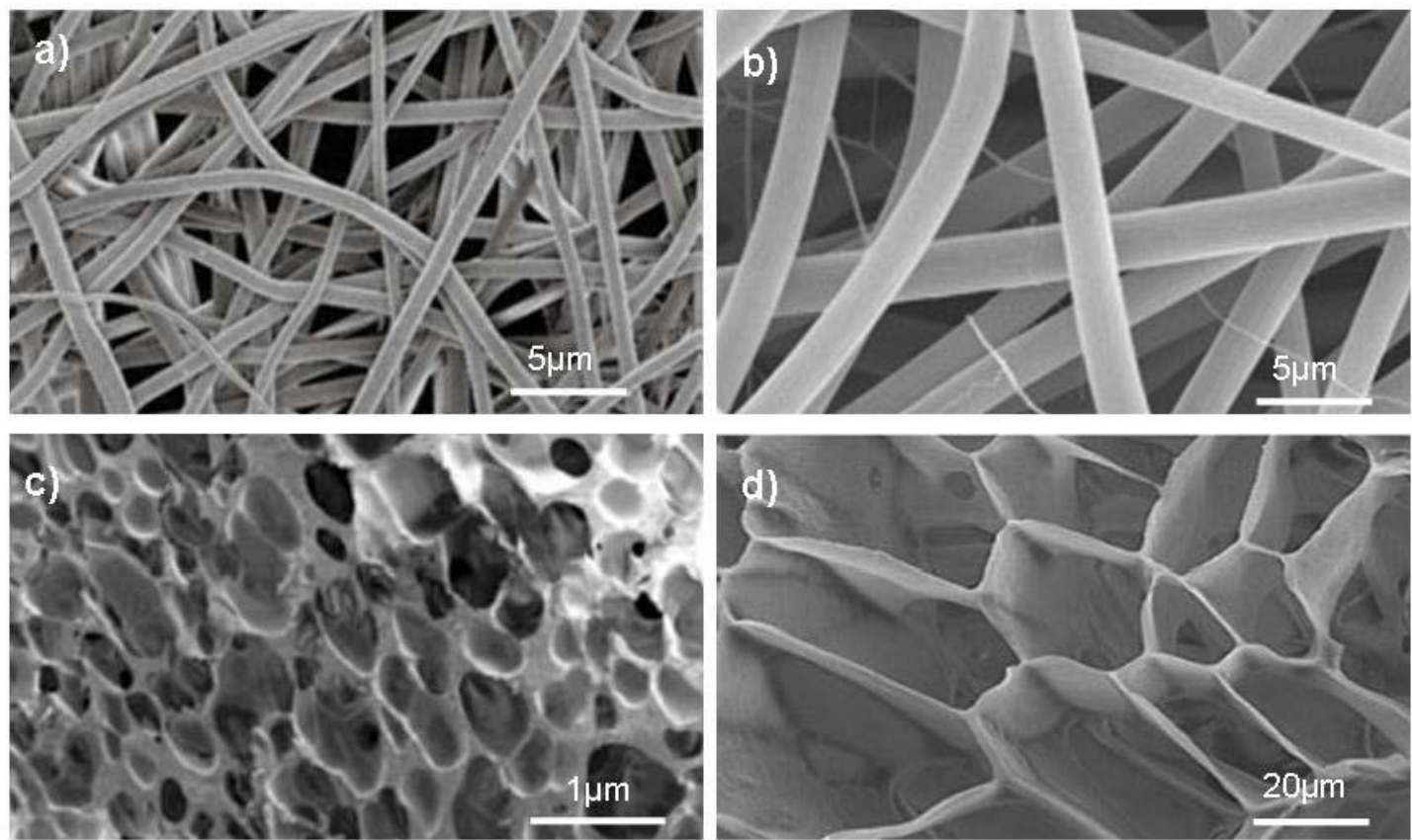

Figure 12. SEM images of (a) electrospun PLA fibres [175], (b) electrospun PLLA/gelatin composite [176], (c) PLA +5\% tricalcium phosphate TCP produced by gas foaming [177] and (d) nHAP/PLLA produced by TIPS [178]. Reprinted with permission from Refs. [175], [176], [177] and [178].

Recently, poly(L-lactic acid)/exfoliated montmorillonite clay/salt solutions were electrospun followed by salt leaching/gas foaming [186]. The resultant scaffold structure contained both nano- and micro-sized pores offering a combination of cell growth and blood vessel invasion micro-dimensions along with nanodimensions for nutrient and metabolic waste transport. Polymer matrix nanocomposites have been also proposed for drug delivery/release applications. The addition of nanoparticles can provide a barrier to drug release allowing slower and more controlled release, and reduced swelling and improved mechanical integrity of hydrogel-based nanocomposites [187, 188]. Figure 12 shows PLA nanocomposite scaffolds prepared by using different techniques. 


\subsubsection{Processing strategies for nanocomposite scaffolds}

There are many techniques/methods to process biomaterial nanocomposites into various scaffolds. These include conventional techniques such as impregnation and sintering ceramic scaffolds processing, solvent casting and particulate leaching, gas foaming, non-woven fibres, fibre knitting, phase separation/emulsion freeze drying or electrospinning techniques. Emerging fabrication techniques are under development particularly solid free form fabrication techniques including 3D printing and fused deposition techniques. Characteristics differentiating the various techniques include the use of solvents, temperature, pressure, or pore creating agents. Three dimensional resorbable polymer scaffolds with very high porosities $(97 \%)$ can be produced using the thermally induced phase separation (TIPS) technique to give controlled macro-and microstructures suitable as scaffolds for tissues such as nerve, muscle, tendon, ligament, intestine, bone, and teeth [173, 189, 190]. The obtained scaffolds are highly porous with anisotropic tubular morphology and extensive pore interconnectivity. Microporosity of TIPS produced foams, their pore morphology, mechanical properties, bioactivity and degradation rates can be controlled by varying the polymer concentration in solution, volume fraction of the secondary phase, quenching temperature and the polymer and solvent used as discussed in a previous review paper [173]. Briefly, the polymer is dissolved in a solvent and stirred overnight to obtain a homogeneous polymer solution. A given amount of glass or ceramic powder can be added into the polymer solution. The mixture is transferred into a flask and sonicated. Thereafter, the flask is quenched in liquid nitrogen, the frozen mixture is transferred into a cooling bath and connected to a vacuum pump. The solvent is sublimated and dried at room temperature in a vacuum oven until reaching a constant weight [231]. Maquet et al. [191, 192] developed highly porous PDLLA/Bioglasss composite scaffolds prepared by TIPS with bimodal and anisotropic pore structures composed of tubular macropores of $100 \mu \mathrm{m}$, interconnected with micropores of 10$50 \mu \mathrm{m}$ in diameter. In vitro studies in phosphate-buffered saline at $37{ }^{\circ} \mathrm{C}$ showed that addition of Bioglasss increased water absorption and weight loss in comparison to pure polymer foams [191, 192]. The molecular weight was found to decrease less within the composite foams, possibly due to the dissolution of alkaline ions from the Bioglass providing a $\mathrm{pH}$ buffering effect. Both the PDLLA/Bioglass composites and the neat PDLLA foams retained their structural integrity until the end of the experiment (16 weeks), which means degradation was still in the early stages.

Solvent casting of biocomposite scaffolds involves the dissolution of the polymer in an 
organic solvent, mixing with the filler phase, and casting the solution into a predefined 3D mould. The solvent is subsequently allowed to evaporate [117]. The main advantage of this processing technique is the easy fabrication without the need of specialised equipment. The primary disadvantages of solvent casting are: (1) the limitation in the shapes (typically flat sheets and tubes are the only shapes that can be formed); (2) the possible retention of toxic solvent within the polymer; and (3) the denaturation of the proteins and other molecules incorporated into the polymer by the use of solvents. Based on this method, a 3D structure of controlled porosity can be formed when combined with particle leaching and microsphere packing. Solvent casting, in combination with particulate leaching involves casting a polymer solution with water soluble particulates into a mould. After the evaporation of the solvent, the particulates are leached away using water to form the pores of the scaffold. The process is easy to carry out, but it works only for thin membranes or very thin $3 \mathrm{D}$ specimens. The method shares similar advantages and disadvantages with the solvent casting technique [193]. There has been little work done on producing bioactive polymer-ceramic scaffolds using particle leaching. Certainly, a drawback of this technique is achieving pore interconnectivity at low porogen (salt/sucrose) loadings, as many of the porogen particles may remain trapped. Nevertheless, composites based on calcium phosphate inclusions with variable and graded porosity have been produced using this route [194-196]. In thicker sample preparation, it is very difficult to remove all the soluble particulates from the polymer matrix [195]. A modified method using laminated thin sheets overcomes the particulate leaching problem [196], but layering of thin porous sheets is time consuming and allows for only a limited number of connected pore networks. The extensive use of solvents in this method also presents a difficulty, as any residuals of the solvent would hinder the cell attachment and proliferation onto the scaffold [197]. However low toxicity solvents can be used in this technique and residues brought down to acceptable levels for application [198].

Electrostatic spinning, also commonly known as electrospinning, is a method that uses a highvoltage electric field, usually $10-20 \mathrm{kV}$, to form solid ultra-fine or even nanoscale (diameter $<100 \mathrm{~nm}$ ) fibres from a suspended droplet of polymer melt or solution through a nozzle [199]. The process involves application of an electrostatic field to the end of a capillary tube where the polymer is suspended. A polymer jet is formed when the surface tension of the droplet is overcome by the electrostatic charge. The solvent evaporates from the jet, which elongates and becomes thinner due to the instable process. An electrically charged polymer is then left behind, which is solidified and collected on a grounded surface. Many parameters can 
influence the transformation of polymer solutions into nanofibres through electrospinning: the solution properties such as viscosity, elasticity, conductivity, and surface tension, governing variables such as hydrostatic pressure in the capillary tube, electric potential at the capillary tip, and the gap (distance between the tip and the collecting screen), and ambient parameters such as solution temperature, humidity, and air velocity in the electrospinning chamber [200]. One of the most important aspects related with electrospinning is the fibre diameter that depends primarily on the jet size as well as on the polymer contents in the jets [201]. Although this method usually falls in the class of techniques that create unordered scaffolds, with recent technology developments, the fibres can be aligned in order to provide cells or tissues with directional cues. Yang et al. [202] demonstrated that by collecting the PLLA fibre jets on a rotating plate, aligned electrospun fibre scaffolds can be made. Electrospinning process and the nanofibrous matrices thus fabricated have gained tremendous interest, also due to the structural similarity to the tissue extracellular matrix, the processing availability to a wide range of materials, as well as simple set-up and operation at low cost. Several studies have reported the performance of nanofibrous materials in guiding cells to initially adhere to and spread over the material, as well as further triggering them to secrete the appropriate ECM molecules targeted to the skin, blood vessel, cartilage, muscle, adipose, nerve and bone [203-207]. In the bone reconstruction area, the electrospun nanofibres have also attracted considerable attention aimed at identifying suitable material compositions and exploiting them into electrospinning [208, 209]. Combining the nanocomposite approach and the electrospinning process, Lee et al. [186] developed a robust dual-porosity scaffold structure for a facile transport of metabolic nutrients and wastes through the nano-sized pores and for the cell implantation and blood vessel invasion through the micro-sized pores. The montmorillonite nano-sized platelets were incorporated into PLLA solution, which was subsequently electrospun and mechanically entangled by a cold compression moulding process for a robust 3-dimensional scaffold structure. Using a salt leaching/gas forming method, micro-sized pores were developed in the electrospun fibre bundles giving a dualporosity scaffold structure. Compared with the pristine PLLA scaffold, the developed nanocomposite fibrous scaffold structure exhibited increased strength and improved structural integrity during the biodegradation process. The nanocomposite scaffold systems also exhibited many tiny pinholes desirably generated on the scaffold walls without serious fragmentation during biodegradation reactions. 


\subsubsection{Mechanical properties of PLA nanocomposite scaffolds}

Nanocomposite approach allows both local and bulk modulation of the material mechanical properties [117, 210]. The mechanical properties of biodegradable polymers may be modulated using nanometric engineered structures taking advantage of the inherent high surface area-volume ratio of nanomaterials [211]. In our previous work we showed by dynamic-mechanical analysis (DMA) how single wall carbon nanotubes (SWCNTs) are able to modify the relaxation mechanism in PLLA nanocomposites [127]. PLLA and SWCNTs showed a good interface affinity, inducing an increase in DMA storage modulus which was caused by a reduction in the polymer chain molecular mobility at the PLLA/SWCNTs interface. The PLLA/SWCNTs-COOH nanocomposite based on functionalised carbon nanotubes (SWCNTs-COOH), exhibited a better interaction whit the polymer matrix, than pristine SWCNT based nanocomposites, as indicated by the highest storage modulus and by the greatest shift in the glass transition temperature attributed to the partial decrease in PLLA chain mobility due to the presence of SWCNTs and COOH groups [212]. Moreover, Bianco et al. [185] recently investigated the microstructure, microarchitecture, and viscoelastic behaviour of electrospun PLLA/d-HAP hybrid nanocomposite mats based on Ca-deficient nanohydroxyapatite. The authors demonstrated that d-HAP contents affected the viscoelastic properties of the electrospun mats and induced a decrease in the storage modulus. The cellmaterial cytocompatibility, studied in vitro by murine bone marrow mesenchymal stem cells (mBM-MSCs), indicated that the hybrid fibrous architecture provided a suitable environment for stem cell culture processes and the electrospun nanocomposite mats are considered to be potential substrates for culturing primary mBM-MSCs. In tissue engineering, stem cell-based regenerative approaches need biomaterials that drive stem cell performance and effectiveness of an implanted device. The proof-of-principle is that stem cells sense the chemical/physical properties of biomaterials and respond thus changing their fate. For instance, the stiffness of matrix has been shown to be important for inducing mesenchymal stem cells toward diverse differentiated cell lineages [97-99, 213-215]. The surface physical properties of substrates caused changes in cell adhesion-ligand presentation and influenced the commitment of mesenchymal stem cells [215]. To prove this theory, we explored in our laboratory whether chemical/physical properties of biomaterials could drive multipotent and pluripotent stem cell differentiation directly in the absence of exogenous soluble differentiating agents [216]. We used polymeric nanocomposite formulations based on PLLA, to generate three fibre mats with comparable architecture and different chemical and mechanical properties: neat 
microfibrous electrospun PLLA and PLLA nanocomposites loaded with 1 wt.-\% or 8 wt.-\% d-HAp. We selected adult human mesenchymal stem cells isolated from bone marrow (hBMMSCs) based on their multipotential ability as traditional stem cells, embryonic stem cells (ESCs) and induced pluripotent stem cells (iPSCs) generated from somatic differentiated cells that are gaining momentum in drug discovery. Compared to neat PLLA, nanocomposites electrospun mats presented similar large interconnected voids within the fibres, resulting in a 3D network, and showed a significant reduction of viscoelastic properties, both storage and loss modulus, with the corresponding increase of d-HAP [185]. Addition of d-HAP to PLLA changes the topography, chemistry and the viscoelastic properties of polymer matrix and, specifically, induces the osteogenic differentiation independently of the stem cell type selected. We demonstrated that the nanocomposite electrospun PLLA loaded with d-HAP promotes osteogenic differentiation of hBM-MSCs, iPSCs and ESCs in the absence of exogenous osteogenic inducers [216]. We suggest that the biological phenomena might be the result of the nanocomposite properties modulation.

Moreover uniform graft-HAP (g-HAP)/PLLA nanocomposites were successfully prepared by Hong et al. [217] and exhibited improved mechanical properties compared to corresponding PLLA/HAP nanocomposites. Especially at g-HAP content of 4 wt.- $\%$, the PLLA/g-HAP showed a maximum in tensile strength, bending strength, and impact energy due to the grafted-PLLA molecules, which played a role of tie molecules between the fillers and the PLLA matrix, and to the g-HAP particles which were uniformly distributed in the composites and played the role of the heterogeneous nucleating agents in the PLLA matrix. The PLLA/gHAP composites also demonstrated improved cell compatibility due to the good biocompatibility of the HAP nanoparticles and the more uniform distribution of the g-HAP nanoparticles on the film surface. Finally, the effects of scaffold composition on the physical properties, adhesion, and growth of bovine articular chondrocytes on poly(lactic acid) /poly(glycolic acid) (PGA) nanocomposites were evaluated by Moran et al. [218]. Nonwoven meshes of PGA were coated with PLA, using a solvent evaporation technique that resulted in composites with fractional PLA contents ranging from 0 to $68 \%$. The compressive modulus of scaffolds increased linearly with the addition of PLA, ranging from less than $1 \mathrm{kPa}$ for PGA to approximately $20 \mathrm{kPa}$ for scaffolds with $68 \%$ PLA content. The authors proved as cells seeded onto $27 \%$ PLA scaffolds increased 3-fold in number over 4 weeks in culture, whereas cells seeded onto $68 \%$ PLA increased only 2-fold in number providing important information for the design of scaffolds for cartilage tissue engineering. 


\subsubsection{Electrical properties of PLA nanocomposite scaffolds}

Electrical properties of the bionanocomposite substrates are important issue in cell interaction, in order to direct cell growth, since they can conduct electricity stimulus into the tissue healing process $[219,220]$. Although induced cell adhesion, migration, and orientation in response to electrical stimulus have been well documented using two-dimensional (2D) cultured cells [221], electrically induced cellular behaviours in the 3D scaffolds remain in part unknown. Application of electrical stimulus could then offer a novel physical approach for controlling cell growth and differentiation in cell based therapy and engineered tissue constructs by regulating cell adhesion and orientation.

Electrical properties of the polymers could be modulated by introducing conductive nanostructures, such as metal nanoparticles (e.g. silver, gold) and carbon nanostructures (e.g. nanotubes, graphene, nanofibres, nanodiamond) [222-226]. Carbon nanotubes (CNTs) have clearly demonstrated their capability as fillers in diverse multifunctional nanocomposites. The addition of CNT decreased the electrical resistivity $(\rho)$ values of biodegradable polymer films [227-232], by several orders of magnitude at very low percolation thresholds $(<0.1 \mathrm{wt} .-\%)$ of CNTs in polymer matrices without compromising other performance aspects of the polymers such as their low weight, optical clarity, low melt viscosities, etc. [233]. In order to obtain a conductive nanocomposite, carbon nanotubes must form a three dimensional conductive network in the polymer above a critical concentration, known as percolation threshold, $p c$ [234], where a transition from non-conducting to conducting state occurs. Numerous studies show that the percolation threshold and conductivity depend strongly on the polymer type and synthesis method, aspect ratio of CNTs, disentanglement of CNT agglomerates, uniform spatial distribution of individual CNTs and degree of alignment. A wide range of values for conductivity and percolation thresholds of CNT composites have been reported in the literature during the last decade, depending on the processing method, polymer matrix and nanotube type [229]. Among the carbon structures, SWCNTs were the most effective fillers to reduce the resistivity of biodegradable polymer films. The addition of SWCNT lowered the $\rho$

of PLLA film from $1.6 \times 10^{5} \Omega \mathrm{cm}$ to values lower than $1 \times 10^{2} \Omega \mathrm{cm}$ (filler concentration of $10 \%$ wt.). Furthermore, even the addition of $1 \%$ wt. SWCNTs caused dramatic decrease in $\rho$ from $1.6 \times 10^{5}$ to $3-4 \times 10^{3} \Omega \mathrm{cm}$. Such high effects of SWCNTs can be ascribed to its needlelike structure, which obliges SWCNTs to effectively contact with each other [235]. For example when an alternating current is applied to the substrate, nanocomposites of PLA and MWCNTs have been shown to increase osteoblast proliferation and calcium production [219]. 
For instance, a 80/20 (w/w) PLA/CNT biodegradable composite exhibited ideal electrical conductivity for bone growth while PLA was an insulator and not appropriate for electrically stimulating bone growth. Specifically, the PLA/CNT composite promoted a $46 \%$ increase in osteoblast proliferation and a $307 \%$ increase in calcium content after electrical stimulation for 2 and 21 days compared to neat PLA, respectively [219]. These studies indicated that the CNTs/CNFs and their composites can serve as osteogenic scaffolds with good cytocompatibility properties, reinforced mechanical properties and improved electrical conductivity to effectively enhance bone tissue growth.

Significant efforts have been devoted to fabricate various biomaterials to satisfy specific clinical requirements. Recently researchers have employed the electrospinning technique in the incorporation of multiwall carbon nanotubes/hydroxyapatite hybrid nanoparticles into PLLA matrix membranes to satisfy the specific requirements of guided tissue regeneration [236]. This work represented the first trial on the fabrication of a biomedical membrane which possesses dual biological functions. This new type of membrane showed excellent dual biological functions and satisfied the requirement of the guided tissue regeneration (GTR) technique in spite of its monolayer structure. The combination of different nanostructures represents a valuable strategy to integrate the functions of components in multi-hybrid systems in order to obtain multifunctional materials [237, 238]. Misra et al. [239] incorporated MWCNTs in a novel bioresorbable/bioactive composite, for the first time, developing a ternary nanocomposite scaffolds combining three different materials. The addition of MWCNTs to bioactive composite materials makes a new highly conductive material, since it produces a three-dimensional electrical conducting network. The MWCNT composites obey Ohm's law and exhibit classic ohmic conduction. An attractive strategy for the achievement of this goal is represented by the use of a new class of hybrid nanomaterials, consisting in CNT-clay systems prepared by direct catalytic chemical vapour deposition (CCVD) growth of CNT on the clay [240]. Santangelo et al. [241] proposed the development of novel PLA based nanocomposites endowed with improved performance. This was accomplished thanks to the incorporation of CNT-clay hybrids into poly(L-lactide) containing about 4.0 mol.-\% of D-lactoyl units (PDLLA). The authors studied the influence of clay on the electrical properties and advantages in using hybrid fillers and they proved that the conductive component (CNT) is mainly responsible for the sizable conductivity enhancement (6-9 orders of magnitude) with respect to the insulating PDLLA (conductivity, $\sigma=1 \cdot 10^{-10}$ $\mathrm{S} / \mathrm{m})$. Nonetheless, the results obtained suggest that clay and CNT exert a synergistic action in 
improving the polymer properties.

\subsection{PLA nanotopography and cellular response}

Cell-substrate interactions are crucial in many biological phenomena. Knowledge of these interactions is a key part in order to understand many fundamental biological questions and to design innovative medical devices. Topography was first identified to influence cell behaviour as early as 1911 when Harrison observed the guidance of cells along the fires of a spider web [242]. To date several groups have demonstrated that surface topography (random/ordered reliefs, patterns, etc.) and surface chemical composition could drive cell adhesion, proliferation, migration and differentiation [97-100, 243]. Various biomaterial characteristics are intercorrelated. Topographic features also influence other aspects of the interaction between biomaterial and biological environment such as hydrophilicity/hydrophobicity (lotus effect), surface energy etc. [118].

The topographical characteristics determine how biological molecules will be adsorbed onto the substrate and, more particularly, determine the orientation of the adsorbed molecules and, finally, regulate the characteristics of cells in contact with the substrate [244], including cell morphology, rates of movement and cell activation [100,101]. When cells adhere and grow on substrates, cells sense, interpret, and integrate extracellular signals and respond to them. Thus, signals from biomaterial surfaces, e.g., chemistry, topography, charge, energy and wettability, are critical extracellular stimulators that have the potential to regulate cell behaviour. Since extracellular matrix proteins exhibit abundant nanometer-scale structures that are hypothesised to contribute to cell-matrix signalling. The basement membranes of many tissues exhibit rich nanotopography that interacts directly with adjacent cells [245, 246]. Cells interact with native topographical structures in many ways, often through a phenomenon known as contact guidance [242] that is a leading example of a naturally occurring phenomenon that is characterised by the response of cells to structures at the micron and submicron scale. Contact guidance is an essential component in regulation cell migration, which is modulated by organised ECM proteins [247]. The role of contact guidance can also be important in the migration of individual cells, or groups of cells or tissue [248]. Studies on substratum topography effects have shown that cells display differential behaviour depending on the topographic "scale" and "feature". For example, anisotropic micro- or nanometer scale ridges and grooves have been shown to induce contact-guided cell alignment in the anisotropic direction [249]. This contact guidance was positively correlated with focal contact 
formation and cytoskeletal organization [250]. Another topographic feature potentially affecting cell behaviour is isotropic micro-or nanometer scale topographies that have evenly or randomly distributed features (pits, islands, holes, etc.) throughout the substrate surface [251-259]. Most of studies examining isotropic features have focused on differential cell responses, such as adhesion and differentiation, as a function of topographic scale, including nanoscale island height. These studies aim to develop cell-adhesive or non-adhesive substrates depending on the topographic scale.

Although the fundamental interactions occur on the molecular scale there is an interesting and unique synergistic connection between the nanometer and the micrometer length scale. Nanoscaled topography has been receiving increasing attention because of its resemblance to in-vivo surroundings. Cells in their natural environment interact with extracellular matrix components in the nanometer scale. Topographical cues in the micron and nanoscale regime represent a powerful and effective method for controlling cell behaviour.

\subsubsection{Nanofabrication and surface modification methods}

Nanofabrication techniques, including electron beam lithography $(10 \mathrm{~nm})$, colloidal particle adsorption $(5 \mathrm{~nm})$, microcontact printing $(200 \mathrm{~nm})$, and self-organising or self-assembling systems $(10 \mathrm{~nm})$, have expanded cell-substratum interaction studies to the nanometer range [116]. Surface nanotopography may be created using a number of techniques ranging from lithographic micro- and nanofabrication to produce ordered features to chemical etching, electrospinning that represents an attractive approach to the fabrication of fibrous biomaterials, which introduces the concept of biomimetic nanofibres for tissue regeneration, and colloidal lithography for random distributions [117]. Therefore, many surface engineering approaches have been followed in order to introduce useful nanotopographical feature to the polymer without changing bulk properties for activating specific biological responses [260, 261]. Plasma processes, for example, may easily modify the surface morphology (e.g. micro/nanostructured coatings with tuneable roughness and shape of structures, or with etching processes, possibly combined with masking techniques like colloidal lithography) $[118,119,262]$. Plasma surface modification, as economical and effective material processing technique, is gaining popularity in the biomedical field. It is able to change the surface chemical composition of the processed material as well as improve the latter's properties such as wettability, adhesion, dyeability, refractive index, hardness, chemical inertness, lubricity and biocompatibility [263-265]. Plasma etching, in which materials are ablated via reactions 
with active species generated in the plasma to form volatile products, can create the desirable micro-and nano-features on the biomaterials to meet the requirement of biocompatibility in vivo.

Self-assembly can be used to create ordered hierarchical structures of bulk materials and ordered surfaces to control cell-biomaterial interaction. Polymer demixing techniques, one of the self-organising systems, utilize polymeric phase separation during a critical high-speed spin-casting process. Phase separation using slightly immiscible polymer blends [251-257] or diblock copolymers $[266,267]$ results in a rise of topographic features of ca. 10-100 nm scale. This technique can control the topographic features (pits, ribbons, or islands in case of blends; spheres, lamellae, cylinders, or bicontinuous in case of copolymers) by varying the polymer composition or copolymer structure and the size of a particular feature by varying the concentration of the spin-casting solution. Random topographical features created by grit blasting, sintering and polymer demixing were found to enhance cell adhesion and spreading [251, 268, 269], while ordered topographical features created by photolithography and electrochemical micromachining have been shown to induce the orientation of focal contacts $[251,269,270]$.

\subsubsection{Cell response to PLA nanotopography}

Since, as mentioned, cell attachment, proliferation and differentiation strongly depend on the chemical and physical properties of the biomaterial surface in tissue engineering many studies were performed in order to understand the correlation between surface topography and cell behaviour. Most of studies have focused on cell responses such as adhesion, proliferation and differentiation as a function of topographic scale.

Wan et al. [271] prepared two surfaces patterned with islands and pits. The micro-and nanoscales of the resulting islands or pits were 2.2 and $0.45 \mu \mathrm{m}$, respectively. The OCT-1 osteoblast-like cells could grow along the surface of the two different sizes of islands and inside the micro-scale islands. The authors thought that these regular arrays of pits and islands made it possible for cells to have specific mechanical interactions with these substrates. The cell adhesion strength was enhanced due to the nano- or micro-scale roughness compared with the smooth surface control. However, the cell proliferation on the micro-and nanoscale patterned surfaces was not enhanced compared with the control. Milner and Siedlecki [120] demonstrated that when PLLA was patterned with ordered arrays of pillars, having submicron geometries, fibroblast adhesion was observed to increase compared with smooth controls. The 
interaction between cells and nanotopography was clearly shown in Figure 13. They also showed that small changes in PLLA surface area may increase initial cell adhesion, but cell proliferation remained either uniform or decreased compared with smooth controls [172].

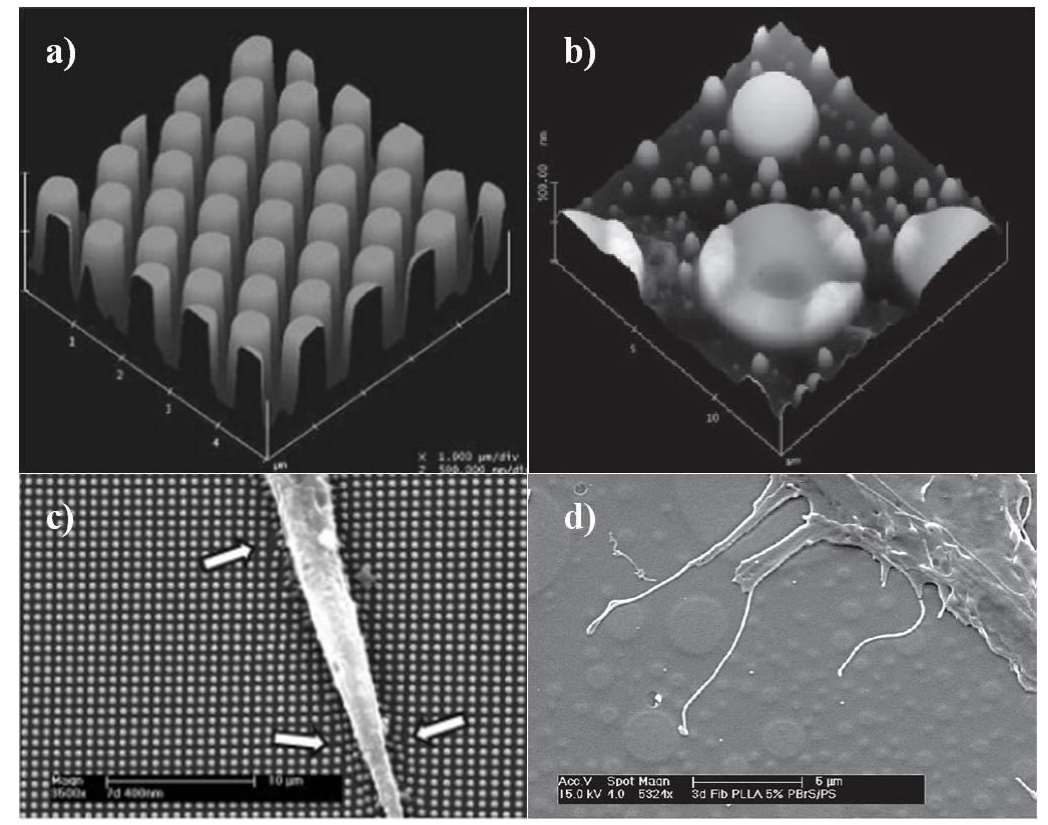

Figure 13. Examples of nanotopography and cell/nanotopography interactions. AFM image of $400 \mathrm{~nm}$ PLLA ordered arrays of pillars produced by soft lithography two stage replica moulding process (A) and SEM image of fibroblast adhere to nanopillar at 7 days (C) [120]. AFM image of PLLA topography obtained by a two-stage replication moulding process based on soft lithography to replicate demixed polymer nanotopography $(B)$ and SEM image of fibroblast no PLLA nanotopography after 3 days (D) [172]. Reprinted with permission from Refs. [120] and [172].

Some studies of PLLA/PS demixed films adds to the body of literature demonstrating that surface topography may be used to influence the cellular response. Nanotextured surfaces stimulate osteoblastic cell adhesion, and this was more distinct for nanoisland relative to nanopit topographies [251]. Considering the important role of integrin-mediated focal adhesion and intracellular signalling in anchorage-dependent cell function, Lim et al. [121] suggested a mechanism by which nanostructured physical signals regulate cell function. The shallower depth nanopits induced significantly greater human fetal osteoblast cell spreading and attachment than did deeper nanopits or flat PLLA surfaces $(14>29>45 \mathrm{~nm}$ deep pits flat PLLA). Furthermore stem cells display an enhanced mechanosensitivity when cultured on specific nanotopographies which has the potential to promote cellular responsiveness to 
mechanical signals. Cells not only prefer nanotopographies, but the size of nanoislands plays a significant role, with an enhanced mechanosensitivity on specific scale nanoislands (approximately $10 \mathrm{~nm}$ ). Although the mechanism by which this occurs is not known, our data, coupled with published data show that focal adhesion and cellular stiffness are increased on nanotopographies of similar sizes, suggest that nanotopography induced differences in cell adhesion and stiffness are positively correlated with cell mechanosensitivity and signalling [273]. Many studies have been conducted using the electrospinning as nanofabrication technique, significant results were found regarding the importance of diameter size demonstrating that surface topography introduced by electrospun fibres of 0.14-2.1 $\mu \mathrm{m}$ affects cell morphology and proliferation [274, 275]. The viability/proliferation and neurite outgrowth of neural stem cell showed a great dependence on fibre diameter, mesh size and fibre arrangement. Cells were induced to spread along the long axis of the aligned fibres with the formation of focal contacts, while randomly oriented cells with spindle and polygonal morphologies were observed on the random fibres. Longer neurite lengths were obtained on the aligned fibres than the random fibres due to contact guidance by the aligned fibres. Thus, this study has not only demonstrated that the topographical cues of fibrous scaffolds, including the fibre arrangement, diameter and mesh size, had significant effects upon cellular behaviour, but also suggests the potential of manipulating the substrate topographical features to facilitate cell proliferation or differentiation functions in the design of fibrous scaffolds [243, 276]. Chemical guiding cues were exploited to stimulate neuron adhesion and neurite outgrowth, using amino-functioned PLLA after phase separation with nanotopography. It was found that improved viability and neurite outgrowth were obtained on the peptide-grafted PLLA films compared to the ordinary PLLA films [277, 278]. Topographical cues in the micron and nanoscale regime represent a powerful and effective method for controlling neuron and glial cell behaviour. Studies have shown that contact guidance can facilitate axon pathfinding, accelerate neurite growth and induce glial cell alignment. Li et al. [279] exploited the concept of haptotaxis via implementation into three-dimensional neural based scaffolds. Polymeric PLLA conduits possessing multiple intralumenal walls and precise topography along the longitudinal axis were fabricated using solvent casting, physical imprinting and a rolling-fusing method. Thus, the proposed conduits can be custom tailored to resorb in parallel with the healing process. Applications for these scaffolds include autograft substitutes for peripheral nerve transection or potential use in spinal cord related injuries. We have previously reported that radiofrequency oxygen plasma treatment was effective in changing the surface properties of polylactide polymer [117]. The treatment homogeneously 
functionalised the surface of the PLLA without affecting its bulk properties, changing wettability, roughness or the interaction of proteins with the surface of PLLA polymer, thus improving the stem cell attachment [262, 280].

\section{Conclusions}

Biobased polymers are considered as outstanding candidates to develop "environmentallyfriendly" materials that would also reduce our fuel dependency. Among them, PLA has been recognised to play a major role to achieve such an objective. Although PLA is a versatile polymer with outstanding physical and biological properties, it still requires further improvements in order to fully achieve its potential. The review has comprehensively presented methods of modifying PLA focussing on both packaging and tissue engineering applications. Special attention has been given to provide a detail recount of the inherent mechanisms responsible for the improved properties, in terms of the deformation mechanisms in the case of toughen PLA and the microenvironment that regulate cell behaviour in the case of tissue engineering and regenerative medicine applications. Further understanding of the biology, qualitatively and quantitatively, of cells within their microenvironments and at the tissue-material interface will expand the design space of future biomaterials.

\section{Acknowledgments}

The authors gratefully acknowledge the financial support of the CSIC (2010MA0003). NB thanks the CSIC for a JAE-Pre grant.

The Author Elena Fortunati is the recipient of the fellowship 'L'Oreal Italia per le Donne e la Scienza 2012" for the project "Progettazione, sviluppo e caratterizzazione di biomateriali nanostrutturati capaci di modulare la risposta e il differenziamento delle cellule staminali". 


\section{REFERENCES}

[1] P. Bordes, E. Pollet, L. Averous. Nano-biocomposites: Biodegradable polyester/nanoclay systems, Prog. Polym. Sci. 34 (2009) 125-155.

[2] R. Auras, B. Harte, S. Selke. An overview of polylactides as packaging materials, Macromol. Biosci. 4 (2004) 835-864.

[3] A. Gandini. The irruption of polymers from renewable resources on the scene of macromolecular science and technology. Green Chem. 13 (2011) 1061-1083.

[4] A.J.R. Lasprilla, G.A.R. Martinez, B.H. Lunelli, A.L. Jardini, R. Maciel. Poly-lactic acid synthesis for application in biomedical devices - A review, Biotechnol. Adv. 30 (2012) 321-328.

[5] R. Datta, M. Henry. Lactic acid: recent advances in products, processes and technologies - a review, J. Chem. Technol. Biotechnol. 81 (2006) 1119-1129.

[6] R.E. Conn, J.J. Kolstad, J.F. Borzelleca, D.S. Dixler, L.J. Filer Jr, B.N. Ladu Jr, et al. Safety assessment of polylactide (PLA) for use as a food-contact polymer, Food Chem. Toxicol. 33 (1995) 273-283.

[7] R.M. Rasal, A.V. Janorkar, D.E. Hirt. Poly(lactic acid) modifications, Prog. Polym. Sci. 35 (2010) 338-356.

[8] R.E. Drumright, P.R. Gruber, D.E. Henton. Polylactic acid technology, Adv. Mater. 12 (2000) 1841-1846.

[9] D. Garlotta. A literature review of poly(lactic acid). J. Polym. Environ. 9 (2001) 63-84

[10] G. Kale, R. Auras, S.P. Singh, R. Narayan. Biodegradability of polylactide bottles in real and simulated composting conditions, Polym. Test. 26 (2007) 1049-1061.

[11] K. Fukushima, C. Abbate, D. Tabuani, M. Gennari, G. Camino. Biodegradation of poly(lactic acid) and its nanocomposites, Polym. Degrad. Stab. 94 (2009) 1646-1655.

[12] G. Kale, T. Kijchavengkul, R. Auras, M. Rubino, S.E. Selke, S.P. Singh. Compostability of bioplastic packaging materials:an overview, Macromol. Biosci. 7 (2007) $255-257$.

[13] M.A. Paul, C. Delcourt, M. Alexandre, P. Degee, F. Monteverde, P. Dubois. Polylactide/montmorillonite nanocomposites: study of the hydrolytic degradation, Polym. Degrad. Stab. 87 (2005) 535-542.

[14] P.A. Gunatillake, R. Adhikaru. Biodegradable synthetic polymers for tissue engineering. Eur. Cells Mater. 5 (2003) 1-16.

[15] D. Zhang, M.A. Kandadai, J. Cech, S. Roth, S.A. Curran. Poly(L-lactide) (PLLA)/Multiwalled Carbon Nanotube (MWCNT) Composite: Characterization and Biocompatibility Evaluation, J. Phys. Chem. B 110 (2006) 12910-12915

[16] G.Ruan, S.S. Feng. Preparation and characterization of poly(lactic acid)-poly(ethylene glycol)-poly(lactic acid) (PLA-PEG-PLA) microspheres for controlled release of paclitaxel. Biomaterials 24 (2003) 5037-5044.

[17] R.C. Nagarwal, P.N. Singh, S. Kant, P. Maiti, J.K. Pandit, Chitosan Coated PLA Nanoparticles for Ophthalmic Delivery: Characterization, In-Vitro and In-Vivo Study in Rabbit Eye, J. Biomed. Nanotechol. 6 (2010) 648-657.

[18] S. Samarajeewa, R. Shrestha, Y. Li, L. Karen. Degradability of Poly(Lactic Acid)Containing Nanoparticles: Enzymatic Access through a Cross-Linked Shell Barrier, J. Am. Chem. Soc. 134 (2012) 1235-1242

[19] H. Zhou, J.G. Lawrence, S.R. Bhaduri. Fabrication aspects of PLA-CaP/PLGA-CaP composites for orthopedic applications: A review, Acta Biomater. 8 (2012) 1999-2016

[20] E. Saito, Y. Liu, F. Migneco, S.J. Hollister. Strut size and surface area effects on longterm in vivo degradation in computer designed poly(L-lactic acid) three-dimensional porous scaffolds, Acta Biomater. 8 (2012) 2568-2577 
[21] F. Pu, N.P. Rhodes, Y. Bayon, R. Chen, G. Brans, R. Benne, J.A. Hunt. The use of flow perfusion culture and subcutaneous implantation with fibroblast-seeded PLLAcollagen 3D scaffolds for abdominal wall repair, Biomaterials 31 (2010) 4330-4340

[22] G.L. Jones, A. Motta, M.J. Marshall, A.J.E. Haj, S.H., Cartmell. Osteoblast: Osteoclast cocultures on silk fibroin, chitosan and PLLA films, Biomaterials 30 (2009) 5376-5384

[23] G. Schwach, M. Vert. In vitro and in vivo degradation of lactic acid-based interference screws used in cruciate ligament reconstruction. Int. J. Biol. Macromolec. 25 (1999) 283-91.

[24] G.Z. Papageorgiou, T. Beslikas, J. Gigis, J. Christoforides, D.N. Bikiaris. Crystallization and enzymatic hydrolysis of PLA grade for orthopedics, Adv. Polym. Technol. 29 (2010) 280-299.

[25] G. Schmack, B. Tandler, R. Vogel, R. Beyreuther, R.S. Jacobsen, H.G. Fritz. Biodegradable fibers of poly(L-lactide) produced by high-speed melt spinning and spin drawing. J. Appl. Polym. Sci. 73 (1999) 2785-97.

[26] C. Chen, G. Lv, C. Pan, M. Song, C.H. Wu, D.D. Guo, et al. Poly(lactic acid) (PLA) based nanocomposites - a novel way of drug-releasing. Biomed. Mater. 2 (2007) L1L4.

[27] A.J.R. Lasprilla, G.A.R. Martinez, B.H. Lunelli, A.L. Jardini, R. Maciel R. Biomaterials for application in bone tissue engineering. J. Biotecnol. 150 (2010) S455S455

[28] Y. Ikada, H. Tsuji. Biodegradable polyesters for medical and ecological applications, Macromol. Rapid Commun. 21 (2000) 117-132.

[29] B. Gupta, N. Revagade, J. Hilborn. Poly(lactic acid) fiber: An overview, Prog Polym Sci. 32 (2007) 455-82.

[30] H. Li, M.A. Huneault. Effect of nucleation and plasticization on the crystallization of poly(lactic acid), Polymer 48 (2007) 6855-6866

[31] L. Cabedo, J.L. Feijoo, M.P. Villanueva, J.M. Lagaron, E. Gimenez. Optimization of biodegradable nanocomposites based on aPLA/PCL blends for food packaging applications, Macromol. Symp. 223 (2006) 191-197

[32] K.S. Anderson, K.M. Schreck, M.A. Hillmyer. Toughening polylactide, Polym. Rev. 48 (2008) 85-108.

[33] H.Z. Liu, J.W. Zhang. Research Progress in Toughening Modification of Poly(lactic acid), J. Polym. Sci., Part B: Polym. Phys. 49 (2011) 1051-1083.

[34] M. Alexandre, P. Dubois. Polymer-layered silicate nanocomposites: preparation, properties and uses of a new class of materials. Mat. Sci. Eng. R. 28 (2000) 1-63

[35] E. Ruiz-Hitzky, A. Van Meerbeek. in Handbook of Clay Science (Eds. F. Bergaya, B.K.G. Theng, G. Lagaly), Elsevier, Amsterdam 2006, Ch. 10.

[36] M. Darder, P. Aranda, E. Ruiz-Hitzky. Bionanocomposites: A new concept of ecological, bioinspired, and functional hybrid materials, Adv. Mater. 19 (2007) 13091319

[37] J.W. Rhim, S.I. Hong, C.S. Ha. Tensile, water vapor barrier and antimicrobial properties of PLA/nanoclay composite films, Lwt-Food Science and Technology, 42 (2009) 612-617

[38] E. Nieddu, L. Mazzucco, P. Gentile, T. Benko, V. Balbo, R. Mandrile, G. Ciardelli. Preparation and biodegradation of clay composites of PLA, React. Fucnt. Polym. 69 (2009) 371-379

[39] D. Lewitus, S. McCarthy, A. Ophir, S. Kenig. The effect of nanoclays on the properties of PLLA-modified polymers part I: Mechanical and thermal properties, J. Polym. Environ. 14 (2006) 171-177 
[40] B. Li, F.X. Dong, X.L. Wang, J. Yang, D.Y. Wang, Y.Z. Wang. Organically modified rectorite toughened poly(lactic acid): Nanostructures, crystallization and mechanical properties, Eur. Polym. J. 45 (2009) 2996-3003

[41] N. Lin, J. Huang, P.R. Chang, J.W. Feng, J.H. Yu. Surface acetylation of cellulose nanocrystal and its reinforcing function in poly(lactic acid), Carbohyd. Polym. 83 (2011) 1834-1842

[42] G. Choudalakis, A.D. Gotsis. Permeability of polymer/clay nanocomposites: A review, Eur. Polym. J. 45 (2009) 967-84.

[43] H.J. Lehermeier, J.R. Dorgan, J.D. Way. Gas permeation properties of poly(lactic acid), J. Membr. Sci. 190 (2001) 243-251.

[44] T. Hideko, O. Rumiko, D. Hiroyuki, K. Fujie. Water vapor permeability of poly(lactide)s: Effects of molecular characteristics and crystallinity, J. Appl. Polym. Sci. 99 (2006) 2245-52.

[45] A. Guinault, C. Sollogoub, V. Ducruet, S. Domenek. Impact of crystallinity of poly(lactide) on helium and oxygen barrier properties, Eur. Polym. J. 48 (2012) 77988.

[46] M. Cocca, M.L.D. Lorenzo, M. Malinconico, V. Frezza. Influence of crystal polymorphism on mechanical and barrier properties of poly(L-Lactic acid), Eur. Polym. J. 47 (2011) 1073-80.

[47] N. Delpouve, G. Stoclet, A. Saiter, E. Dargent, S. Marais. Water barrier properties in biaxially drawn poly(lactic acid) Films, J. Phys. Chem. B 116 (2012) 4615-25.

[48] S.S. Ray, M. Bousmina. Biodegradable polymers and their layered silicate nano composites: In greening the 21st century materials world, Prog. Mater. Sci. 50 (2005) 962-1079.

[49] S.S. Ray, K. Yamada, M. Okamoto, K. Ueda. New polylactide-layered silicate nanocomposites. 2. Concurrent improvements of material properties, biodegradability and melt rheology, Polymer 44 (2003) 857-66.

[50] S.S. Ray, K. Yamada, M. Okamoto, Y. Fujimoto, A. Ogami, K. Ueda. New polylactide/layered silicate nanocomposites. 5. Designing of materials with desired properties, Polymer 44 (2003) 6633-46.

[51] J.H. Chang, Y. An, G.S. Sur. Poly(lactic acid) nanocomposites with various organoclays. I. Thermomechanical properties, morphology, and gas permeability, J. Polym. Sci. Part B: Polym. Phys, 41 (2003) 94-103.

[52] E. Picard, E. Espuche, R. Fulchiron. Effect of an organo-modified montmorillonite on PLA crystallization and gas barrier properties, Appl. Clay Sci. 53 (2011) 58-65.

[53] M. Zenkiewicz, J. Richert, A. Rozanski. Effect of blow moulding ratio on barrier properties of polylactide nanocomposite films, Polym. Test. 29 (2010) 251-7.

[54] N. Bitinis, R. Verdejo, E.M. Maya, E. Espuche, P. Cassagnau, M.A. Lopez-Manchado. Physicochemical properties of organoclay filled polylactic acid/natural rubber blend bionanocomposites, Compos. Sci. Technol. 72 (2012) 305-313.

[55] M. Sanchez-Garcia, J. Lagaron. On the use of plant cellulose nanowhiskers to enhance the barrier properties of polylactic acid, Cellulose 17 (2010) 987-1004.

[56] M.D. Sanchez-Garcia, E. Gimenez, J.M. Lagaron. Morphology and barrier properties of solvent cast composites of thermoplastic biopolymers and purified cellulose fibers, Carbohyd. Polym. 71 (2008) 235-44.

[57] H. Fukuzumi, T. Saito, T. Wata, Y. Kumamoto, A. Isogai. Transparent and high gas barrier films of cellulose nanofibers prepared by TEMPO-mediated oxidation, Biomacromolecules 10 (2009) 162-5.

[58] J.F. Martucci, R.A. Ruseckaite. Three-layer sheets based on gelatin and Poly(lactic acid), Part 1: Preparation and properties, J. Appl. Polym. Sci. 118 (2010) 3102-10. 
[59] A.J. Svagan, A. Akesson, M. Cardenas, S. Bulut, J.C. Knudsen, J. Risbo J, et al. Transparent films based on PLA and montmorillonite with tunable oxygen barrier properties, Biomacromolecules 13 (2012) 397-405.

[60] J.Y. Nam, S.S. Ray, M. Okamoto. Crystallization behavior and morphology of biodegradable polylactide/layered silicate nanocomposite, Macromolecules 36 (2003) 7126-7131

[61] Y.W. Di, S. Iannace, E. Di Maio, L. Nicolais. Poly(lactic acid)/organoclay nanocomposites: Thermal, rheological properties and foam processing, J. Polym. Sci. Part B: Polym. Phys. 43 (2005) 689-698

[62] M. Pluta, M.A. Paul, M. Alexandre, P. Dubois. Plasticized polylactide/clay nanocomposites. I. The role of filler content and its surface organo-modification on the physico-chemical properties, J. Polym. Sci. Part B: Polym. Phys. 44 (2006) 299-311.

[63] L. Suryanegara, A.N. Nakagaito, H. Yano. Thermo-mechanical properties of microfibrillated cellulose-reinforced partially crystallized PLA composites, Cellulose 17 (2010) 771-778.

[64] E. Fortunati, I. Armentano, Q. Zhou, A. Iannoni, E. Saino, L. Visai, L.A. Berglund, J.M. Kenny. Multifunctional bionanocomposite films of poly(lactic acid), cellulose nanocrystals and silver nanoparticles, Carbohyd. Polym. 87 (2012) 1596-1605.

[65] A.H. Pei, Q. Zhou, L.A. Berglund. Functionalized cellulose nanocrystals as biobased nucleation agents in poly(L-lactide) (PLLA) - Crystallization and mechanical property effects, Compos. Sci. Technol. 70 (2010) 815-821

[66] N. Lin, P.R. Huang, J.W. Feng, J.H. Yu. Surface acetylation of cellulose nanocrystal and its reinforcing function in poly(lactic acid), Carbohyd. Polym. 83 (2011) 18341842

[67] A.L. Goffin, J.M. Raquez, E. Duquesne, G. Siqueira, Y. Habibi, A. Dufresne, P. Dubois. From interfacial ring-opening polymerization to melt processing of cellulose nanowhisker-filled polylactide-based nanocomposites, Biomacromolecules 12 (2011) 2456-2465

[68] www.plasticseurope.org

[69] G. Kale, R. Auras, S.P. Singh. Comparison of the degradability of poly(lactide) packages in composting and ambient exposure conditions, Packag. Technol. Sci. 20 (2007) 49-70

[70] E. Petinakis, X. X. Liu, L. Yu, C. Way, P. Sangwan, K. Dean, S. Bateman, G. Edward. Biodegradation and thermal decomposition of poly(lactic acid)-based materials reinforced by hydrophilic fillers, Polym. Degrad. Stabil. 95 (2010) 1704-1707

[71] A.P. Mathew, K. Oksman, M. Sain. Mechanical properties of biodegradable composites from poly lactic acid (PLA) and microcrystalline cellulose (MCC), J. Appl. Polym. Sci. 97 (2005) 2014-2025.

[72] S.S. Ray, K. Yamada, M. Okamoto, K. Ueda. Control of biodegradability of polylactide via nanocomposite technology, Macromol. Mater Eng. 288 (2003) 203-208

[73] S.R. Lee, H.M. Park, H. Lim, T.Y. Kang, X.C. Li, W.J. Cho, C.S. Ha. Microstructure, tensile properties, and biodegradability of aliphatic polyester/clay nanocomposites, Polymer 43 (2002) 2495-2500

[74] K. Fukushima, D. Tabuani, C. Abbate, M. Arena, L. Ferreri. Effect of sepiolite on the biodegradation of poly(lactic acid) and polycaprolactone, Polym. Degrad. Stabil. 95 (2010) 2049-2056.

[75] J.W. Rhim, S.I. Hong, H.M. Park, P.K. W.Ng. Preparation and characterization of chitosan-based nanocomposite films with antimicrobial activity, J. Agr. Food Chem. 54 (2006) 5814-5822 
[76] M.A. Paul, M. Alexandre, P. Degee, C. Henrist, A. Rulmont, P. Dubois. New nanocomposite materials based on plasticized poly(L-lactide) and organo-modified montmorillonites: thermal and morphological study, Polymer. 44 (2003) 443-450.

[77] K.Y. Lee, J.J. Blaker, A. Bismarck. Surface functionalisation of bacterial cellulose as the route to produce green polylactide nanocomposites with improved properties. Compos. Sci. Technol. 69 (2009) 2724-2733

[78] L.C. Tome, R.J.B. Pinto, E. Trovatti, C.S.R. Freire, A.J.D. Silvestre, C.P. Neto, A. Gandini. Transparent bionanocomposites with improved properties prepared from acetylated bacterial cellulose and poly(lactic acid) through a simple approach, Green Chem. 13 (2011) 419-427

[79] M. Pluta, A. Galeski, M. Alexandre, M.A. Paul, P. Dubois. Polylactide/montmorrillonite nanocomposites and microcomposites prepared by melt blending: Structure and some physical properties, J. Appl. Polym. Sci. 86 (2002) 1497-1506

[80] M.D. Sanchez-Garcia, J.M. Lagaron. Novel clay-based nanobionanocomposites of biopolyesters with synergistic barrier to UV light, gas and vapour, J. Appl. Polym. Sci. 118 (2010) 188-199.

[81] L. Petersson, K. OKsman. Biopolymer based nanocomposites: Comparing layered silicates and microcrystalline cellulose as nanoreinforcements, Compos. Sci. Technol. 66 (2006), 2187-2196

[82] C. Thellen, C. Orroth, D. Froio, D. Ziegler, J. Lucciarini, R. Farrell, et al. Influence of montmorillonite layered silicate on plasticized poly(L-lactide) blown films, Polymer. 46 (2005) 11716-11727.

[83] V.P. Martino, A. Jimenez, R.A. Ruseckaite, L. Averous. Structure and properties of clay nano-biocomposites based on poly(lactic acid) plasticized with polyadipates, Polym. Adv. Technol. 22 (2011) 2206-2213.

[84] M.A. Paul, C. Delcourt, M. Alexandre, P. Degee, F. Monteverde, A. Rulmont, et al. (Plasticized) polylactide/(organo-)clay nanocomposites by in situ intercalative polymerization, Macromol. Chem. Phys. 206 (2005) 484-498.

[85] M. Pluta, M.A. Paul, M. Alexandre, P. Dubois. Plasticized polylactide/clay nanocomposites. II. The effect of aging on structure and properties in relation to the filler content and the nature of its organo-modification, J. Polym. Sci. Part B: Polym. Phys. 44 (2006) 312-325.

[86] S. Tanoue, A. Hasook, Y. Iemoto, T. Unryu. Preparation of poly(lactic acid)/poly(ethylene glycol)/organoclay nanocomposites by melt compounding, Polym. Compos. 27 (2006) 256-263.

[87] G.X. Chen, H.S. Kim, E.S. Kim, J.S. Yoon. Compatibilization-like effect of reactive organoclay on the poly(L-lactide)/poly(butylene succinate) blends, Polymer 46 (2005) 11829-11836.

[88] G.X. Chen, J.S. Yoon. Morphology and thermal properties of poly(Llactide)/poly(butylene succinate-co-butylene adipate) compounded with twice functionalized clay, J. Polym. Sci., Part B: Polym. Phys. 43 (2005) 478-487.

[89] V. Ojijo, H. Cele, S.S. Ray. Morphology and Properties of Polymer Composites Based on Biodegradable Polylactide/Poly (butylene succinate)-co-adipate Blend and Nanoclay, Macromol. Mater Eng. 296 (2011) 865-877.

[90] A. Hasook, S. Tanoue, Y. Iemoto, T. Unryu. Characterization and mechanical properties of poly(lactic acid)/poly(epsilon-caprolactone)/organoclay nanocomposites prepared by melt compounding, Polym. Eng. Sci. 46 (2006) 1001-1007.

[91] S.S. Sabet, A.A. Katbab. Interfacially Compatibilized Poly(lactic acid) and Poly(lactic acid)/Polycaprolactone/Organoclay Nanocomposites with Improved Biodegradability 
and Barrier Properties: Effects of the Compatibilizer Structural Parameters and Feeding Route, J. Appl. Polym. Sci. 111 (2009) 1954-1963.

[92] O.H. Arroyo, M.A. Huneault, B.D. Favis, M.N. Bureau. Processing and Properties of PLA/Thermoplastic Starch/Montmorillonite Nanocomposites, Polym. Compos. 31 (2010) 114-127.

[93] N. Bitinis, A. Sanz, A. Nogales, R. Verdejo, M.A. Lopez-Manchado, T.A. Ezquerra. Deformation mechanisms in polylactic acid/natural rubber/organoclay bionanocomposites as revealed by synchrotron X-ray scattering, Soft Matter, 8 (2012) 8990-8997

[94] E. Fortunati, I. Armentano, A. Iannoni, M. Barbale, S. Zaccheo, M. Scavone, L. Visai, J.M. Kenny. New Multifunctional Poly(lactide acid) Composites: Mechanical, Antibacterial, and Degradation Properties, J. Appl. Polym. Sci. 124 (2012) 87-98.

[95] E. Fortunati, D. Puglia, C. Santulli, F. Sarasini, J.M. Kenny. Biodegradation of phormium tenax/poly(lactic acid) composites, J. Appl. Polym. Sci. 125 (2012) E239E247.

[96] L.L. Hench and J.M. Polak, Third-generation biomedical materials, Science 295 (2002) 1014-7.

[97] S. Martino, F. D’Angelo, I. Armentano, R. Tiribuzi, M. Pennacchi, M. Dottori, et al. Hydrogenated amorphous carbon nanopatterned film designs drive human bone marrow mesenchymal stem cell cytoskeleton architecture, Tissue Eng. Part A, 15 (2009) 3139-49.

[98] F. D’Angelo, I. Armentano, S. Mattioli, L. Crispoltoni, R. Tiribuzi, G.G. Cerulli, et al. Micropatterned hydrogenated amorphous carbon guides mesenchymal stem cells towards neuronal differentiation, Eur. Cell Mater. 20 (2010) 231-44.

[99] K.A. Kilian, B. Bugarija, B.T. Lahn, and M. Mrksich. Geometric cues for directing the differentiation of mesenchymal stem cells, Proc. Natl. Acad. Sci. USA 107 (2010) 4872-7.

[100] R.J. McMurray, N. Gadegaard, P.M. Tsimbouri, K.V. Burgess, L.E. McNamara, R. Tare, et al., Nanoscale surfaces for the long-term maintenance of mesenchymal stem cell phenotype and multipotency, Nature Mater. 10 (2011) 637-44.

[101] A. Curtis, C. Wilkinson, Topographical control of cells, Biomaterials 18 (1997) 157383.

[102] A.R. Boccaccini, M. Erol, W.J. Stark, D. Mohn, Z. Hong, J.F. Mano. Polymer/bioactive glass nanocomposites for biomedical applications: A review, Compos. Sci. Technol. 70 (2010) 1764-76.

[103] D.A. Stone, L.T.J. Korley. Bioinspired polymeric nanocomposites, Macromolecules, 43 (2010) 9217-26.

[104] S. Singh, S.S. Ray. Polylactide based nanostructured biomaterials and their applications, J. Nanosci. Nanotechnol. 7 (2007) 2596-615.

[105] X. Liu, P.X. Ma. Polymeric scaffolds for bone tissue engineering, Ann. Biomed. Eng. 32 (2004) 477-86.

[106] K.M. Woo, V.J. Chen, P. Ma. Nano-fibrous scaffolding architecture selectively enhances protein adsorption contributing to cell attachment, J. Biomed. Mater. Res. A 67 (2003) 531-7.

[107] A. Kumari, S.K. Yadav, S.C. Yadav. Biodegradable polymeric nanoparticles based drug delivery systems, Colloid. Surfaces B 75 (2010) 1-18.

[108] L. Zhang L, T.J. Webster. Nanotechnology and nanomaterials: Promises for improved tissue regeneration, Nano Today 4 (2009) 66-80.

[109] T. Dvir, B.P. Timko, D. S. Kohane, Nanotechnological strategies for engineering complex tissues, Nat. Nanotechnol. 6 (2011) 13-22. 
[110] V.J. Mohanraj, Y. Chen. Nanoparticles - A review, Trop. J. Pharm. Res. 5 (2006) 56173.

[111] Y. Lu, S.C. Chen, Micro and nano-fabrication of biodegradable polymers for drug delivery, Adv. Drug delivery reviews 56 (2004) 1621-33.

[112] A.S. Amritkar, H.S. Chaudhari, D.A. Narkhede, D.K. Jain, D.T. Baviskar, Nanotechnology for biomedical applications, Int. J. Pharm. Sci. Rev. Res. 8 (2011) 45-53.

[113] P. Decuzzi, R. Pasqualini, W. Arap, M. Ferrari, Intravascular delivery of particulate systems: does geometry really matter? Pharm. Res. 26 (2009) 235-43.

[114] C.P. Reis, R.J. Neufeld, A.J. Ribeiro, F. Veiga, Nanoencapsulation i. methods for preparation of drug loaded polymeric nanoparticles, Nanomedicine 2 (2006) 8-21.

[115] A. Vila, A. Sanchez, M. Tobio, P. Calvo, M.J. Alonso. Design of biodegradable particles for protein delivery, J. Control. Release 78 (2002) 15-24.

[116] A. Curtis, C. Wilkinson. Nanotechniques and approaches in biotechnology, Trends Biotechnol. 19 (2001) 97-101.

[117] I. Armentano, G. Ciapetti, M. Pennacchi, M. Dottori, V. Devescovi, D. Granchi, et al. Role of PLLA plasma surface modifi-cation in the interaction with human marrow stromal cells, J. App. Polym. Sci. 114 (2009) 3602-11.

[118] R. Morent, N. De Geyter, T. Desmet, P. Dubruel, C. Leys. Plasma surface modification of biodegradable polymers: A review, Plasma Process. Polym. 8 (2011) 171-90.

[119] E. Sardella, P. Favia, R. Gristina, M. Nardulli, R. d'Agostino. Plasma-aided micro-and nanopatterning processes for biomedical applications, Plasma Process. Polym. 3 (2006) 456-69.

[120] K.R. Milner, C.A. Siedlecki. Submicron poly(L-lactic acid) pillars affect fibroblast adhesion and proliferation, J. Biomed. Mater. Res. A 82 (2007) 80-91.

[121] J.Y. Lim, A.D. Dreiss, S. Zhou, J.C. Hansen, C.A. Siedlecki, R.W. Hengstebeck, et al. The regulation of integrin-mediated osteoblast focal adhesion and focal adhesion kinase expression by nanoscale topography, Biomaterials 28 (2007) 1787-97.

[122] M. Okamoto. Biodegradable polmer/layered silicate nanocomposites: A review, J. Ind. Eng. Chem. 10 (2004) 1156-81.

[123] T.B. Liu, C. Burger, B. Chu. Nanofabrication in polymer matrices, Prog. Polym. Sci. 28 (2003) 5-26.

[124] K. Ishizu, K. Tsubaki, A. Mori, S. Uchida, Architecture of nanostructured polymers, Prog. Polym. Sci. 28 (2003) 27-54.

[125] S.J. Park, K. Li, S.K. Hong. Preparation and characterization of layered silicate modified ultrahigh-molecular-weight polyethylene nanocomposites, J. Ind. Eng. Chem. 11 (2005) 561-6.

[126] J.W. Kim, S.G. Kim, H.J. Choi, and M.S. Jhon, Synthesis and electrorheological properties of polyaniline- $\mathrm{Na}^{+}$-montmorillonite suspensions, Macromol. Rapid. Commun. 20 (2009) 450-2.

[127] I. Armentano, L. Marinucci, M. Dottori, S. Balloni, E. Fortunati, M. Pennacchi, et al., Novel poly(L-lactide) plla/swnts nanocomposite for biomedical applications: Material characterization and biocompatibility evaluation. novel poly(L-lactide) PLLA/SWCNTs nanocomposite for biomedical applications: Material characterization and biocompatibility evaluation, J. Biomat. Sci. Polym. E 22 (2011) 541-556.

[128] I. Armentano, M. Dottori, E. Fortunati, S. Mattioli, J.M. Kenny. Biodegradable polymer matrix nanocomposites for tissue engineering: A review, Polym. Degrad. Stabil. 95 (2010) 2126-46. 
[129] S.D. Gavande, H.D. Salunke, P.L. Ughade, D.T. Baviskar, D.K. Jain. Biodegradable nanoparticle: emerging research area for novel drug delivery, J. Pharm. Res. 5 (2012) 169-173.

[130] S.P. Egusquiaguirre, M. Igartua, R.M. Hernndez, J.L. Pedraz. Nanoparticle delivery systems for cancer therapy: advances in clinical and preclinical research, Clin. Transl. Oncol. 14 (2012) 83-93.

[131] Q. He, W. Yuan, J. Liu, R. Zhang. Study on in vivo distribution of liver-targeting nanopaticles encapsulating thymidine kinase gene (TK gene) in mice, J. Mater. Sci. Mater. Med. 19 (2008) 559-65.

[132] D.B. Shenoy, M.M. Amiji. Poly(ethylene oxide)-modified poly(epsilon caprolactone) nanoparticles for targeted delivery of tamoxifen in breast cancer, Int. J. Pharm. 293 (2005) 261-70.

[133] F. Alexis, E. Pridgen, L.K. Molnar, O.C. Farokhzad, Factors affecting the clearance and biodistribution of polymeric nanoparticles, Mol. Pharm. 5 (2008) 505-15.

[134] C.E. Mora-Huertas, H. Fessi, A. Elaissari. Influence of process and formulation parameters on the formation of submicron particles by solvent displacement and emulsificationdiffusion methods. critical comparison, Adv. Colloid. Interfac. 163 (2011) 90-122.

[135] V. Lassalle, M.L. Ferreira, PLA nano- and microparticles for drug delivery: An overview of the methods of preparation, Macromol. Biosci. 7 (2007) 767-783.

[136] H. Xie, J.W. Smith. Fabrication of PLGA nanoparticles with a fluidic nanoprecipitation system, J. Nanobiotechnology 8 (2010) 1-8.

[137] H. Rafati, A.G.A. Coombes, J. Adler, J. Holland, S.S. Davis. Protein-loaded poly(D,Llactide-co-glycolide) microparticles for oral administration: formulation, structural and release characteristics, J. Control. Release 43 (1997) 89-102.

[138] Y.P. Li, Y.Y. Pei, X.Y. Zhang, Z.H. Gu, Z.H. Zhou, W.F. Yuan, et al. PEGylated PLGA nanoparticles as protein carriers: synthesis, preparation and biodistribution in rats,. J. Control. Release 71 (2001) 203-11.

[139] H. Suh, B. Jeong, R. Rathi, S.W. Kim. Regulation of smooth muscle cell proliferation using paclitaxel-loaded poly(ethylene oxide) poly(lactide/glycolide )nanospheres, J. Biomed. Mater. Res. 42 (1998) 331-8.

[140] C.X. Song, V. Labhasetwar, H. Murphy, X. Qu, R. Humphrey, R.J. Shebuski, et al. Formulation and characterization of biodegradable nanoparticles for intravascular local drug delivery, J. Control. Release 43 (1997) 197-212.

[141] Y.H. Cheng, L. Illum, S.S. Davis, A poly(D,L-lactide-co-glycolide) microsphere depot system for delivery of haloperidol, J. Control. Release 55 (1998) 203-12.

[142] R. Liu, G.H. Ma, Y.H. Wan, Z.G. Su. Influence of process parameters on the size distribution of PLA microcapsules prepared by combining membrane emulsification technique and double emulsion-solvent evaporation method, Colloid. Surfaces B 45 (2005) 144-153.

[143] D. Lemoine, V. Preat. Polymeric nanoparticles as delivery system for influenza virus glycoproteins, J. Control. Release 54 (1998) 15-27.

[144] M.J. Alonso, M.D. Blanco, Development and characterization of protein-loaded poly(lactide-co-glycolide) nanospheres, Eur. J. Pharm. Biopharm. 43 (1998) 287-94.

[145] H. Fessi, F. Puisieux, J.P. Devissaguet, N. Ammoury, S. Benita. Nanocapsule formation by interfacial polymer deposition following solvent displacement, Int. J. Pharm. 55 (1989) R1-R4.

[146] J. Molpeceres, M. Guzman, M. Aberturas, M. Chacon, L. Berges. Application of central composite designs to the preparation of polycaprolactone nanoparticles by solvent displacement, J. Pharm. Sci. 85 (1996) 206-13. 
[147] S. Guterres, H. Fessi, G. Barrat, F. Puisieux, J. Devissaguet. Poly(D,L-lactide) nanocapsules containing diclofenac: I. formulation and stability study, Int. J. Pharm. 113 (1995) 57-63.

[148] M. Chacon, L. Berges, J. Molpeceres, M. Aberturas, M. Guzman. Optimized preparation of poly d,l(lactic-glycolic) microspheres and nanoparticles for oral administration, Int. J. Pharm. 141 (1996) 81-91.

[149] D. Quintanar-Guerrero, E. Allemann, H. Fessi, E. Dolker. Preparation techniques and mechanisms of formation of biodegradable nanoparticles from preformed polymers, Drug. Dev. Ind. Pharm. 24 (1998) 1113-28.

[150] E. Allemann, R. Gurnay, and E. Doelker. Preparation of aqueous polymeric nanodispersions by a reversible salting-out process: influence of process parameters on particle size, Int. J. Pharm. 87 (1992) 247-53.

[151] E. Allemann, J.C. Leroux, R. Gurnay, E. Doelker, In vitro extended-release properties of drug-loaded poly(D,L-lactic) acid nanoparticles produced by a salting-out procedure, Pharm. Res. 10 (1993): 1732-7.

[152] R. Bodmeier, J. McGinity. Polylactic acid microspheres containing quinidine base and quinidine sulphate prepared by the solvent evaporation method. iii. Morphology of the microspheres during dissolution studies, J. Microencapsul. 5 (1988) 325-30.

[153] M. Blanco-Prieto, K. Besseghir, P. Orsolini, F. Heimgartner, Deuschel, C.H. Merkle, et al. Importance of the test medium for the release kinetics of a somatostatin analogue from poly(D,L-lactide-co-glycolide) microspheres, Int. J. Pharm. 184 (1999) 243-50.

[154] J. Vasir, K. Tambwekar, S. Garg S. Bioadhesive microspheres as a controlled drug delivery system, Int. J. Pharm. 255 (2003) 13-32.

[155] M. Gaumet, R. Gurny, F. Delie. Fuorescent biodegradable PLGA particles with narrow size distributions: Preparation by means of selective centrifugation, Int. J. Pharm. 342 (2007) 222-30.

[156] J. Panyam, V. Labhasetwar. Biodegradable nanoparticles for drug and gene delivery to cells and tissue, Adv. Drug Deliver. Rev. 55 (2003) 329-47.

[157] M. Jahanshahi, Z. Babaei. Protein nanoparticle: A unique system as drug delivery vehicles, Afr. J. Biotechnol. 7 (2008) 4926-34.

[158] R. Manchanda, A. Fernandez-Fernandez, A. Nagesetti, A.J. McGoron. Preparation and characterization of a polymeric (PLGA) nanoparticulate drug delivery system with simultaneous incorporation of chemotherapeutic and thermo-optical agents, Colloid. Surfaces B 75 (2010) 260-7.

[159] L.E. van Vlerken, M.M. Amiji. Multi-functional polymeric nanoparticles for tumourtargeted drug delivery, Expert Opin. Drug Deliv. 3 (2006) 205-16.

[160] N. Rescignano, M. Amelia, A. Credi, J.M. Kenny, I. Armentano. Morphological and thermal behaviour of porous biopolymeric nanoparticles, Eur. Polym. J. DOI: 10.1016/j.eurpolymj.2012.05.005.

[161] R. Rajesh Singh, J.W.J. Lillard. Nanoparticle-based targeted drug delivery, Exp. Mol. Pathol. 86 (2009) 215-23.

[162] A.H. Faraji, P. Wipf, Nanoparticles in cellular drug delivery, Bioorg. Med. Chem. 17 (2009) 2950-62.

[163] M. Hamoudeh, H. Salim, D. Barbos, C. Paunoiu, H. Fessi. Preparation and characterization of radioactive dirhenium decacarbonyl-loaded PLLA nanoparticles for radionuclide intratumoral therapy, Eur. J. Pharm. Biopharm. 67 (2007) 597-611.

[164] S. Sant, V. Nadeau, P. Hildgen. Effect of porosity on the release kinetics of propafenone-loaded PEG-g-PLA nanoparticles, J. Control. Release 107 (2005) 20314. 
[165] S. Prabha, V. Labhasetwar. Nanoparticle-mediated wild-type p53 gene delivery results in sustained antiproliferative activity in breast cancer cells, Mol. Pharmacol. 1 (2004) $211-9$.

[166] V. Mailanderand, K. Landfester. Interaction of nanoparticles with cells, Biomacromolecules 10 (2009) 2379-400.

[167] Y. Yang, Z. Zhang, L. Chen, W. Gu, Y. Li. Galactosylated poly(2-(2aminoethyoxy)ethoxy)phosphazene/dna complex nanoparticles: in vitro and in vivo evaluation for gene delivery, Biomacromolecules 11 (2010) 927-33.

[168] S. Kakade, D.S. Manickam, H. Handa, G. Mao, D. Oupick. Transfection activity of layer-by-layer plasmid DNA/polyetylenimine films deposited on PLGA microparticles, Int. J. Pharm. 365 (2009) 44-52.

[169] M. Andersen, A. Lichawska, A. Arpanaei, S.M. Rask Jensen, H. Kaur, D. Oupicky et al. Surface functionalisation of PLGA nanoparticles for gene silencing, Biomaterials 31 (2010) 5671-7.

[170] J.K. Kim, J.S. Park, H.N. Yang, D.G. Woo, S.Y. Jeon, H.J. Do, et al. The use of biodegradable PLGA nanoparticles to mediate SOX9 gene delivery in human mesenchymal stem cells (HMSCS) and induce chondrogenesis, Biomaterials, 32 (2011) 268-78.

[171] D.W. Schaefer, R.S. Justice. How nano are nanocomposites?, Macromolecules 40 (2007) 8501-17.

[172] H.A. Liu, T.J. Webster. Nanomedicine for implants: a review of studies and necessary experimental tools, Biomaterials 28 (2007) 354-69.

[173] A.R. Boccaccini, V. Maquet, Bioresorbable and bioactive polymer/bioglass(r) composites with tailored pore structure for tissue engineering applications, Compos. Sci. Technol. 63 (2003) 2417-29.

[174] E. Wintermantel, S. Ramakrishna, J. Mayer, K.W. Leong KW. Biomedical applications of polymer-composite materials: A review, Compos. Sci. Technol. 61 (2001) 1189-224.

[175] S.T. McCullen, D.R. Stevens, W.A. Roberts, L.I. Clarke, S.H. Bernacki, et al. Characterization of electrospun nanocomposite scaffolds and biocompatibility with adipose-derived human mesenchymal stem cells, Int. J. Nanomedicine. 2 (2007) 253263.

[176] Q. Cai, Q. Xu, Q. Feng, X. Cao, X. Yang, X. Deng. Biomineralization of electrospun poly(L-lactic acid)/gelatin composite fibrous scaffold by using a supersaturated simulated body using with continuous $\mathrm{CO}_{2}$ bubbling, Appl. Surf. Sci. 257 (2011) 10109-10118.

[177] M.O. Montjovent, L. Mathieu, H. Schmoeke, S. Mark, P.E. Bourban, et al. Repair of critical size defects in the rat cranium using ceramic-reinforced PLA scaffolds obtained by supercritical gas foaming, J. Biomed. Mater. Res.-A 83 (2007) 41-51.

[178] E. Nejati, M. Mirzadeh Hand Zandi. Synthesis and characterization of nanohydroxyapatite rods/poly(L-lactide acid) composite scaffolds for bone tissue engineering. Compos. Part A-Appl. S. 39 (2008) 1589-1596.

[179] M.P. Prabhakaran, J. Venugopal, S. Ramakrishna, Electrospun nanostructured scaffolds for bone tissue engineering, Acta Biomaterialia 5 (2009) 2884-93.

[180] S.V. Dorozhkin, M. Epple, Biological and medical significance of calcium phosphates,Angew. Chem. Int. Ed. Engl. 41 (2002) 3130-46.

[181] H.W. Kim, H.H. Lee, G.S. Chun. Bioactivity and osteoblast responses of novel biomedical nanocomposites of bioactive glass nanofiber filled poly(lactic acid), J. Biomed. Mater. Res, 85A (2008) 651-63. 
[182] C.C.P.M. Verheyen, J.R. de Wijn, C.A. van Blitterswijk, K. de Groot, P.M. Rozing. Hydroxyapatite/poly(L-lactide) composites: an animal study on push-out strengths and interface histology, J. Biomed. Mater. Res. 27 (1993) 433-44.

[183] J.A. Roether, A.R. Boccaccini, L.L. Hench, V. Maquet, S. Gautier, R. Jrme. Development and in vitro characterisation of novel bioresorbable and bioactive composite materials based on polylactide foams and bioglass for tissue engineering applications, Biomaterials 23 (2002) 3871-8.

[184] P.X. Ma, R. Zhang, G. Xiao, R. Franceschi. Engineering new bone tissue in vitro on highly porous poly(hydroxyl acids)/hydroxyapatite composite scaffolds, J. Biomed. Mater. Res. 54 (2001) 284-93.

[185] A. Bianco, B.M. Bozzo, I. Cacciotti, C. del Gaudio, I. Armentano, M. Dottori, et al. Poly(L-lactic acid)/calcium-deficient nanohydroxyapatite electrospun mats for murine bone marrow stem cell cultures, J. Bioact. Compat. Pol. 26 (2011) 225-41.

[186] Y.H. Lee, J.H. Lee, I.G. An, C. Kim, D.S. Lee, Y.K. Lee, et al. Electrospun dualporosity structure and biodegradation morphology of montmorillonite reinforced PLLA nanocomposite scaffolds, Biomaterials 26 (2005) 3165-72.

[187] Q. Zhang, L. Zha, J. Ma, B. Liang. A novel route to the preparation of poly(nisopropylacrylamide) microgels by using inorganic clay as a crosslinker, Macromol. Rapid Commun. 28 (2007) 116-20.

[188] K. Haraguchi, H.J. Li. Mechanical properties and structure of polymer-clay nanocomposite gels with high clay content, Macromolecules 39 (2006) 1898-905.

[189] P.X. Ma, R. Zhang. Microtubular architecture of biodegradable polymer scaffolds, J. Biomed. Mater. Res. 56 (2001) 469-77.

[190] V. Maquet, D. Martin, F. Scholtes, R. Franzen, J. Schoenen, G. Moonen, et al. Poly(D,L-lactide) foams modified by poly(ethylene oxide)-block-poly(D,L-lactide) copolymers and a-FGF: in vitro and in vivo evaluation for spinal cord regeneration, Biomaterials 22 (2001) 1137-46.

[191] V. Maquet, A.R. Boccaccini, L. Pravata, I. Notingher, R. Jerome. Porous poly(hydroxyacid)/bioglass(r) composite scaffolds for bone tissue engineering. i: Preparation and in vitro characterisation, Biomaterials 25 (2004) 4185-94.

[192] V. Maquet, A.R. Boccaccini, L. Pravata, I. Notingher, R. Jerome. Preparation, characterization, and in vitro degradation of bioresorbable and bioactive composites based on bioglass-filled polylactide foams, J. Biomed. Mater. Res. A 66A (2003) 33546, 2003.

[193] C.T. Laurencin, H.H. Lu, Y. Khan. Processing of polymer scaffolds: polymer-ceramic composite foams, volume 705. A. Atala, R.P. Lanza, methods of tissue engineering, academic press, san Diego edition, 2002.

[194] C. Schiller, M. Siedler, F. Peters, M. Epple. Functionally graded materials of biodegradable polyesters and bone-like calcium phosphates for bone replacement. Ceramic Transactions 114 (2001) 97-108.

[195] A.G. Miko, J.S. Temeno. Formation of highly porous biodegradable scaffolds for tissue engineering. Electron. J. Biotech. 13 (2000) 114-9.

[196] A.G. Miko, G. Sarakinos, S.M. Leite, J.P. Vacanti, R. Langer. Laminated threedimensional biodegradable foams for use in tissue engineering, Biomaterials 14 (1993) 323-30.

[197] G.P. Chen, T. Ushida, T. Tateishi. Development of biodegradable porous scaffolds for tissue engineering, Mater. Sci. Eng. C 17 (2001) 63-9.

[198] M.C. Chang, J. Tanaka, XPS study for the microstructure development of hydroxyapatite-collagen nanocomposites crosslinked using glutataldehyde, Biomaterials 23 (2002) 3879-85. 
[199] Z.M. Huang, Y.Z. Zhang, M. Kotaki, S. Ramakrishna, A review on polymer nanofibers by electrospinning and their applications in nanocomposites, Compos. Sci. Technol. 63 (2003) 2223-53.

[200] J. Doshi, D.H. Reneker, Electrospinning process and applications of electrospun fibers, J. Electrostatics 35 (1995) 151-60.

[201] M. Bognitzki, W. Czado, T. Frese, A. Schaper, M. Hellwig, M. Steinhart, et al. Nanostructured fibers via electrospinning, Adv. Mater. 13 (2001):70-2.

[202] F. Yang, R. Murugan, S. Wang, S. Ramakrishna. Electrospinning of nano/micro scale poly(L-lactic acid) aligned fibers and their potential in neural tissue engineering, Biomaterials 26 (2005) 2603-10.

[203] D. Liang, B.S. Hsiao, B. Chu. Functional electrospun nanofibrous scaffolds for biomedical applications, Adv. Drug Deliv. Rev. 59 (2007) 1392-412.

[204] Q.P. Pham, U. Sharma, A.G. Mikos, Electrospinning of polymeric nanofibers for tissue engineering applications: A review, Tissue Eng. 12 (2006) 1197-211.

[205] T.J. Sill, H.A. Recum. Electrospinning: applications in drug delivery and tissue engineering, Biomaterials 29 (2008) 1989-2006.

[206] C.P. Barnes, S.A. Sell, E.D. Boland, D.G. Simpson, G.L. Bowlin. Nanofiber technology: designing the next generation of tissue engineering scaffolds, Adv. Drug Deliv. Rev. 59 (2007) 1413-33.

[207] Z. Ma, M. Kotaki, R. Inai, S. Ramakrishna, Potential of nanofiber matrix as tissue engineering scaffolds, Tissue Eng. 11 (2005) 101-9.

[208] H. Yoshimoto, Y.M. Shin, H. Terai, J.P. Vacanti., A biodegradable nanofiber scaffold by electrospinning and its potential for bone tissue engineering, Biomaterials 24 (2003) 2077-82.

[209] N. Ashammakhi, A. Ndreu, Y. Yang, H. Ylikauppila, L. Nikkola, V. Hasirci, Tissue engineering: a new take-off using nanofiber-based scaffolds, J. Craniofac. Surg. 18 (2007) 3-17.

[210] S.C. Baker, G. Rohman, J. Southgate, N.R. Cameron. The relationship between the mechanical properties and cell behaviour on PLGA and PCL scaffolds for bladder tissue engineering, Biomaterials 30 (2009) 1321-8.

[211] R. Qiao, L.C. Brinson. Simulation of interphase percolation and gradients in polymer nanocomposites, Compos. Sci. Technol. 69 (2009) 491-9.

[212] C.S. Wu, H.T. Liao. Study on the preparation and characterization of biodegradable polylactide/multi-walled carbon nanotubes nanocomposites, Polymer 48 (2007) 444958.

[213] A.J. Engler, S. Sen, H.L. Sweeney, D.E. Discher. Matrix elasticity directs stem cell lineage specification. Cell 126 (2006) 677-89.

[214] N.D. Leipzig, M.S. Shoichet. The effect of substrate stiffness on adult neural stem cell behaviour. Biomaterials 30 (2009) 6867-78.

[215] N. Huebsch, P.R. Arany, A.S. Mao, D. Shvartsman, O.A. Ali, et al. Harnessing traction-mediated manipulation of the cell/matrix interface to control stem-cell fate, Nat. Mater. 9 (2010) 518-26.

[216] F. D'Angelo, I. Armentano, I. Cacciotti, M. Quattrocelli, C. del Gaudio, E. Fortunati, et al. Osteogenic differentiation of multi- and pluri-potent stem cells via modulation of calcium-deficient nanohydroxyapatite poly(L-lactic acid) nanocomposite properties, Biomacromolecules 13 (2012) 1350-60.

[217] Z. Hong, P. Zhang, C. He, X. Qiu, A. Liu, L. Chen, et al. Nano-composite of poly(Llactide) and surface grafted hydroxyapatite: Mechanical properties and biocompatibility, Biomaterials 26 (2005) 6296-304. 
[218] J.M. Moran, D. Pazzano, L.J. Bonassar, Characterization of polylactic acidpolyglycolic acid composites for cartilage tissue engineering, Tissue Eng. 9 (2003) 6370.

[219] P.R. Supronowicz, P.M. Ajayan, K.R. Ullmann, B.P. Arulanandam, D.W. Metzger, R. Bizios. Novel current-conducting composite substrates for exposing osteoblasts to alternating current stimulation, J. Biomed. Mater. Res. 3 (2002) 499-506.

[220] S.Martino, F. D'Angelo, I. Armentano, J.M. Kenny, A. Orlacchio. Stem cellbiomaterial interactions for regenerative medicine. Biotechnol. Adv. 30 (2012) 338351.

[221] E.T. Wang, M. Zhao, J.V. Forrester, C.D. McCaig. Bi-directional migration of lens epithelial cells in a physiological electrical field, Exp. Eye Res. 1 (2003) 29-37.

[222] S. Sun, I. Titushkin, M. Cho. Regulation of mesenchymal stem cell adhesion and orientation in 3D collagen scaffold by electrical stimulus, Bioelectrochemistry 2 (2006) 133-41.

[223] M.S. Dresselhaus, G. Dresselhaus, P.C. Eklund. Science of Fullerenes and Carbon Nanotubes, San Diego: Academic Press, 1996.

[224] B.S. Harrison, A. Atala. Review: carbon nanotube applications for tissue engineering, Biomaterials 28 (2007) 344-53.

[225] M. Dottori, I. Armentano, E. Fortunati, J.M. Kenny. Production and properties of solvent-cast poly( $\varepsilon$-caprolactone) composites with carbon nanostructures, J. Appl. Polym. Sci. 19 (2011) 3544-3552.

[226] Q. Zhang, V.N. Mochalin, I. Neitzel, C.A. Klug, J.G. Zhou, et al. Fluorescent PLLAnanodiamond composites for bone tissue engineering, Biomaterials 32 (2011) 87-94.

[227] H.S. Kim, B.H. Park, J.S. Yoon, H.J. Jin. Macromolecular nanotechnology: Thermal and electrical properties of poly(L-lactide)-graft-multiwalled carbon nanotube composites, Eur. Polym. J. 43 (2007) 1729-1735.

[228] H.S. Kim, Y.S. Chae, B.H. Park, J.S. Yoon, M. Kang, H.J. Jin. Thermal and electrical conductivity of poly(L-lactide)/multiwalled carbon nanotube nanocomposites, Curr. Appl. Phys. 8 (2008) 803-806.

[229] Z. Spitalsky, D. Tasis, K. Papagelis, C. Galiotis. Carbon nanotube-polymer composites: Chemistry, processing, mechanical and electrical properties, Prog. Polym. Sci. 35 (2010) 357-401.

[230] C.F. Kuana, H.C. Kuana, C.C.M. Ma, C.H. Chen. Mechanical and electrical properties of multi-wall carbon nanotube/poly(lactic acid) composites. J. Phys. Chem. Solids. 69 (2008) 1395-1398.

[231] W.M. Chiu, Y.A. Chang, H.Y. Kuo, M.H. Lin, H.C. Wen. A study of carbon nanotubes/biodegradable plastic polylactic acid composites, J. Appl. Polym. Sci. 108 (2008) 3024-3030.

[232] E. Lizundia, J.R. Sarasua, F. D'angelo, A. Orlacchio, S. Martino, J.M. Kenny, I. Armentano. Biocompatible poly (L-lactide)/MWCNT nanocomposites: morphological characterization, electrical properties and stem cell interaction, Macromol. Biosci. DOI: $10.1002 /$ mabi.201200008.

[233] L.P. Krul, A.I. Volozhyn, D.A. Belov, N.A. Poloiko, A.S. Artushkevich, et al. Nanocomposites based on poly-D,L-lactide and multi-wall carbon nanotubes, Biomol. Eng. 24 (2007) 93-95.

[234] D. Stauffer, A. Aharony. Introduction to Percolation Theory, second ed., Taylor \& Francis, Amazon, UK,1992.

[235] H. Tsuji, Y. Kawashima, H. Takikawa, S. Tanaka, Poly(L-lactide)/nano-structured carbon composites: Conductivity, thermal properties, crystallization, and biodegradation, Polymer. 48 (2007) 4213-4225. 
[236] F. Mei, J. Zhong, X. Yang, X. Ouyang, S. Zhang, X. Hu, et al. Improved biological characteristics of poly(L-lactic acid) electrospun membrane by incorporation of multiwalled carbon nanotubes/hydroxyapatite nanoparticles, Biomacromolecules 8 (2007) 3729-3735.

[237] E. Fortunati, F. D'Angelo, S. Martino, A. Orlacchio, J.M. Kenny, I. Armentano, Carbon nanotubes and silver nanoparticles for multifunctional conductive biopolymer composites, Carbon. 49 (2011) 2370-2379.

[238] M. Van der Zande, X.F. Walboomers, B. Olalde, M.J. Jurado, J.I. Alava, et al. Effect of nanotubes and apatite on growth factor release from PLLA scaffolds, J. Tissue. Eng. Regen. Med. 5 (2011) 476-482.

[239] S.K. Misra, P.C.P. Watts, S.P. Valappil, S.R.P. Silva, I. Roy, A.R. Boccaccini. Poly(3hydroxybutyrate)/bioglass composite films containing carbon nanotubes, Nanotechnology 18 (2007) 75701-75708.

[240] C. Milone, D. Manikandan, S. Santangelo, M. Lanza, S. Galvagno, G.Messina. K10 montmorillonite based catalysts for the growth of multiwalled carbon nanotubes through catalytic chemical vapor deposition, Ind. Eng. Chem. Res. 49 (2010) 324-329.

[241] S. Santangelo, G. Gorrasi, R. Di Lieto, S. De Pasquale, G. Patimo, E. Piperopoulos, et al. Polylactide and carbon nanotubes/smectite-clay nanocomposites: Preparation, characterization, sorptive and electrical properties, Appl. Clay. Sci. 53 (2011) 188194.

[242] R.G. Harrison. On the stereotropism of embryonic cells, Science 31 (1911) 279-281.

[243] S. Patel, K. Kurpinski, R. Quigley, B. Gao H Hsiao, M.M. Poo, et al. Bioactive nanofibers: Synergistic effects of nanotopography and chemical signaling on cell guidance, Nano Letters. 7 (2007) 2122-2128.

[244] K. Anselme. Osteoblast adhesion on biomaterials, Biomaterials 21 (2000) 667-681.

[245] S.L. Goodman, P.A. Sims, R.M. Albrecht. Three-dimensional extra-cellular matrix textured biomaterials, Biomaterials 17 (1996) 2087-2095.

[246] G.A. Abrams, S.L. Goodman, P.F. Nealy, M. Franco, C.J. Murphy. Nanoscale topography of the basement membrane underlying corneal epithelium of the rhesus macaque, Cell. Tissue. Res. 299 (2000) 39-46.

[247] K. Wolf, R. Muller, S. Borgmann, E.B. Brocker, P. Fiedl. Amoeboid shape change and contact guidance: T-lymphocyte crawling through fibrillar collagen is independent of matrix remodeling by MMPS and other proteases, Blood. 102 (2003) 3262-3269.

[248] P. Fiedl. Prespecification and plasticity: shifting mechanisms of cell migration, Curr. Opin. Cell. Biol. 16 (2004) 14-23.

[249] A.I. Teixeira, G.A. Abrams, P.J. Bertics, C.J. Murphy, P.F. Nealey. Epithelial contact guidance on well-defined micro- and nanostructured substrates, J. Cell. Sci. 116 (2003) 1881-1892.

[250] S. Britland, H. Morgan, B. Wojiak-Stodart, M. Riehle, A. Curtis, C. Wilkinson. Synergistic and hierarchical adhesive and topographic guidance of BHK cells, Exp. Cell. Res, 228 (1996) 313-325.

[251] J.Y. Lim, J.C. Hansen, C.A. Siedlecki, J. Runt, H.J. Donahue. Human fetal osteoblastic cell response to polymer-demixed nanotopographic interfaces, J. R. Soc. Interface. 2 (2005) 97-108.

[252] M.J. Dalby, M.O. Riehle, H.J.H. Johnstone, S. Affrossman, A.S.G. Curtis. In vitro reaction of endothelial cells to polymer demixed nanotopography, Biomaterials 23 (2002) 2945-2954.

[253] M.J. Dalby, S.J. Yarwood, M.O. Riehle, H.J.H. Johnstone, S. Affrossman, A.S.G. Curtis. Increasing fibroblast response to materials using nanotopography: 
Morphological and genetic measurements of cell response to 13-nm-high polymer demixed islands, Exp. Cell. Resp. 276 (2002) 1-9.

[254] M.J. Dalby, S. Childs, M.O. Riehle, H.J.H. Johnstone, S. Affrossman. Fibroblast reaction to island topography: changes in cytoskeleton and morphology with time, Biomaterials. 24 (2003) 927-935.

[255] M.J. Dalby, D. Giannaras, M.O. Riehle, N. Gadegaard, S. Affrossman. Rapid fibroblast adhesion to $27 \mathrm{~nm}$ high polymer demixed nanotopography, Biomaterials 25 (2004) 77-83.

[256] M.J. Dalby, M.O. Riehle, H.J.H. Johnstone, S. Affrossman, A.S.G. Curtis. Nonadhesive nanotopography: Fibroblast response to poly(n-butyl methacrylate)poly(styrene) demixed surface features, J. Biomed. Mater. Res. 67A (2003) 10251032.

[257] M.O. Riehle, M.J. Dalby, H.J.H. Johnstone, A. MacIntosch, S. Affrossman. Cell behaviour of rat calvaria bone cells on surfaces with random nanometric features, Mater. Sci. Eng. C. 23 (2003) 337-340.

[258] J.M. Rice, J.A. Hunt, J.A. Gallagher, P. Hanarp, D.S. Sutherland, J. Gold. Quantitative assessment of the response of primary derived human osteoblasts and macrophages to a range of nanotopography surfaces in a single culture model in vitro, Biomaterials. 24 (2003) 4799-4818.

[259] M.J. Dalby, N. Gadegaard, M.O. Riehle, C.D. Wilkinson, A.S.G. Curtis. Investigating filopodia sensing using arrays of defined nano-pits down to $35 \mathrm{~nm}$ diameter in size, Int. J. Biochem. Cell. Biol. 36 (2004) 2005-2015.

[260] Y.P. Jiao, F.Z. Cui. Surface modification of polyester biomaterials for tissue engineering, Biomed. Mat. 2 (2007) 24-37.

[261] T.I. Croll, A.J. O'Connor, G.W. Stevens, J.J. Cooper-White. A blank slate layer-bylayer deposition of hyaluronic acid and chitosan onto various surfaces, Biomacromolecules. 7 (2006) 1610-1622.

[262] R. Di Mundo, R. Gristina, E. Sardella, F. Intranuovo, M. Nardulli, A. Milella, et al. Micro-/nanoscale structuring of cell-culture substrates with fluorocarbon plasmas, Plasma, Process. Polym. 7 (2010) 212-223.

[263] P.K. Chu, J.Y. Chen, L.P. Wang, N. Huang. Plasma-surface modification of biomaterials, Mater. Sci. Eng. 36 (2002) 143-206.

[264] X. Qu, W. Cui, F. Yang, C. Min, H. Shen, J. Bei, et al. The effect of oxygen plasma pretreatment and incubation in modified simulated body u-ids on the formation of bone-like apatite on poly(lactide-co-glycolide) (70/30), Biomaterials 28 (2007) 9-18.

[265] H. Shen, X. Hu, J. Bei, S. Wang. The immobilization of basic fibroblast growth factor on plasma-treated poly(lactide-co-glycolide), Biomaterials 29 (2008) 2388-2399.

[266] M. Wang, X. Zhu, S. Wang, L. Zhang. Surface pattern in thin poly(styrenemaleic anhydride) films, Polymer 40 (1999) 7387-7396.

[267] S.H. Hsu, C.M. Tang, C.C. Lin. Biocompatibility of poly $(\varepsilon-$ caprolactone)/poly(ethylene glycol) diblock copolymers with nanophase separation, Biomaterials 25 (2004) 5593-5601.

[268] T.J. Webster, R.W. Siegel, R. Bizios. Osteoblast adhesion on nanophase ceramis, Biomaterials. 20 (1999) 1221-1227.

[269] O. Zinger, G. Zhao, Z. Schwartz, J. Simpson, M. Wieland, D. Landolt, et al. Differential regulation of osteoblasts by substrate microstructural features, Biomaterial. 26 (2005) 1837-1847.

[270] E.T. den Barber, J.E. de Ruijetr, L.A. Ginsel, A.G. von Recum, J.A. Jensen. Orientation of ECM protein deposition, fibroblast cytoskeleton, and attachment 
complex components on silicon microgrooved surfaces, J. Biomed. Mater. Res. 40 (1998) 291-300.

[271] Y.Q. Wan, Y. Wang, Z.M. Liu, X. Qu, B.X. Han, J.Z. Bei, et al. Adhesion and proliferation of oct-1 osteoblast-like cells on micro- and nano-scale topography structured poly(L-lactide), Biomaterials 26 (2005) 4453-4459.

[272] K.R. Milner, C.A. Siedlechi. Fibroblast response is enhanced by poly(L-lactic acid) nanotopography edge density and proximity, Int. J. Nanomedicine. 2 (2007) 201-211.

[273] J.D. Salvi, J.Y. Lim, H.J. Donahue. Increased mechanosensitivity of cells cultured on nanotopographies, J. Biomech. 43 (2010) 3058-3062.

[274] A.S. Badami, M.R. Kreke, M.S. Thompson, J.S. Riffle, A.S. Goldstein. Effect of fiber diameter on spreading, proliferation, and differentiation of osteoblastic cells on electrospun poly(lactic acid) substrates, Biomaterials. 27 (2006) 596-606.

[275] I.K. Kwon, S. Kidoaki, T. Matsuda. Electrospun nano- to microfiber fabrics made of biodegradable copolyesters: structural characteristics, mechanical properties and cell adhesion potential, Biomaterials. 26 (2005) 3929-3939.

[276] L. He, S. Liao, D. Quan, K. Ma, C. Chan, S. Ramakrishna, J. Lu.Synergistic effects of electrospun PLLA fiber dimension and pattern on neonatal mouse cerebellum C17.2 stem cells, Acta. Biomater. 6 (2010) 2960-2969.

[277] L. He, S. Liao, D. Quan, M. Ngiam, C.K. Chan, S. Ramakrishna, et al. The influence of laminin-derived peptides conjugated to lys-capped PLLA on neonatal mouse cerebellum c17.2 stem cells, Biomaterials 30 (2009) 1578-1586.

[278] R. Ravichandran, S. Liao, C.C.H. Ng, C.K. Chan, M. Raghunath, S. Ramakrishna. Effects of nanotopography on stem cell phenotypes, World. J. Stem. Cells. 1 (2009) $55-66$.

[279] J. Li, R. Shi. Short communication fabrication of patterned multi-walled poly-L-lactic acid conduits for nerve regeneration, J. Neurosci. Meth. 165 (2007) 257-264.

[280] E. Sardella, L. Detomaso, R. Gristina, G.S. Senesi, H. Agheli, D.S. Sutherland, et al. Nano-structured cell-adhesive and cell-repulsive plasma-deposited coatings: Chemical and topographical effects on keratinocyte adhesion, Plasma. Process. Polym. 5 (2008) $540-551$. 